\title{
Self-assembled nanoscale photomimetic models: structure and related dynamics
}

\author{
Eduard I. Zenkevich ${ }^{\mathrm{a}, *}$, Christian von Borczyskowski ${ }^{\mathrm{b}}$, Alexander M. Shulga ${ }^{\mathrm{a}}$, \\ Sergei Bachilo ${ }^{\mathrm{a}}$, Ulrich Rempel ${ }^{\mathrm{b}}$, Andreas Willert ${ }^{\mathrm{b}}$ \\ ${ }^{a}$ Institute of Molecular and Atomic Physics, Natl. Acad. Sci. of Belarus, F. Skaryna Avenue 70, 220072 Minsk, Belarus \\ ${ }^{\mathrm{b}}$ Institute of Physics, University of Technology Chemnitz, Reichenhainer Str. 70, 09107 Chemnitz, Germany
}

Received 20 April 2001; in final form 17 September 2001

\begin{abstract}
Using static and time-resolved measurements, dynamics of non-radiative relaxation processes have been studied in self-assembled porphyrin triads of various geometry, containing the main biomimetic components, $\mathrm{Zn}$-porphyrin dimers, free-base extra-ligands (porphyrin, chlorin or tetrahydroporphyrin), and electron acceptors A (quinone or pyromellitimide). The strong quenching of the dimer fluorescence is due to energy and sequential electron transfer (ET) processes to the extra-ligand ( $\sim 0.9-1.7 \mathrm{ps})$, which are faster than a slower ET (34-135 ps) from the dimer to covalently linked $\mathrm{A}$ in toluene at $293 \mathrm{~K}$. The extra-ligand $\mathrm{S}_{1}$-state decay $\left(\tau_{\mathrm{S}}=940-2670 \mathrm{ps}\right)$ is governed by competing processes: a bridge (dimer) mediated long-range $\left(r_{\mathrm{DA}}=18-24 \AA\right.$ ) superexchange ET to an acceptor, and photoinduced hole transfer from the excited extra-ligand to the dimer followed by possible superexchange ET steps to low-lying charge transfer states of the triads. The subsequent ET steps dimer $\rightarrow$ monomer $\rightarrow A$ taking place in the triads, mimic the sequence of primary ET reactions in photosynthetic reaction centers in vivo. (C) 2002 Elsevier Science B.V. All rights reserved.
\end{abstract}

Keywords: Porphyrin supramolecular complexes; Picosecond and femtosecond time-resolved spectroscopy; Fluorescence quenching; Charge and energy transfer

\section{Introduction}

Recent developments in material science show that various functional nanoscale multimolecular nanodevices (optoelectronic gates, photoinduced picosecond molecular switches, photonic wires, and storage units [1]) are based on elementary

\footnotetext{
${ }^{*}$ Corresponding author. Tel.: +375-172-841-563; fax: +375172-840-030.

E-mail address: zenkev@imaph.bas-net.by (E.I. Zenkevich).
}

photoprocesses taking place in native systems. It is well documented that in plants and photosynthetic bacteria, sunlight is initially absorbed by light harvesting pigment-protein antenna complexes in which the electronic excitation energy is efficiently transferred into the photochemical reaction center (RC) [2-5]. Then, in the excited photosynthetic RC the energy of excited states is converted into a stable transmembrane charge separation through a sequence of electron transfer (ET) reactions [6]. All these ET processes are characterised by nearly $100 \%$ quantum efficiency, and the photoinitiated 
charge separation in vivo exhibits the activationless behaviour being highly effective in the solid state at liquid helium temperatures [7]. The mechanisms and dynamics of photoinduced ET, such as charge separation and charge recombination of the product ion pair state are the most fundamental and important problems. At present, some details of the distant ET processes in vivo remain non-understood yet, for instance, spectrostructural correlations, the role of pigment-protein interactions, the relatively weak temperature dependence and high efficiency of charge separation. Additionally, there is an ongoing debate, as to whether ET is sequential for all steps, that is following the shortest pathway along the donor/acceptor array or whether so-called spectator states mediate the process via superexchange without participating in the transfer directly [8]. In spite of the fact that recent experiments provide evidence for a sequential transfer in modified RC's of Rhodobacter sphaeroides at room temperature [9] it cannot be excluded that the superexchange mechanism may play a role at lower temperatures or in different kinds of RC's. Theoretical investigations still allow for this possibility $[10,11]$.

From this point of view, the preparation of multimolecular model assemblies with functional properties to mimic important features of primary photosynthetic events or to gain some insight into the principal possibilities of molecular electronics is one of the most pronounced tendencies of supramolecular photochemistry $[12,13]$. Stimulated by biophysical investigations, the majority of conformationally restricted, structurally and energetically well-defined multiporphyrin arrays have been used recently in order to better understand factors and mechanisms which control the efficiency and directionality of the energy and ET reactions [14-19]. The formation of a variety of models is based on two principally different approaches. One way of the biomimetic chemistry is using the covalent linkage between supposedly essential components [20-37]. The other approach is based on non-covalent interactions of various nature (electrostatic interactions [38,39], hydrogen bonds $[40,41]$, and coordination interactions $[42,43])$. The latter approach provides a synthetically elegant route to a wide variation including both qualitative and quantitative aspects of the composition of supramolecular systems. Based on these two approaches, it has been shown that intracomplex ET may take place on a broad (up to femtosecond) time scale. ET rate constants depend on the energy of the donor, $\mathrm{D}$, locally excited $\mathrm{S}_{1}$ and $\mathrm{T}_{1}$-states, redox properties of interacting donor-acceptor (D-A) components, their mutual geometry and $\mathrm{D}-\mathrm{A}$ intercenter distance as well as on solvent temperature and polarity. In addition, the energy, geometry and chemical nature of the spacer determine the main ET pathways (throughbond, through-space or superexchange mechanisms [10]). The effective charge separation caused by a direct, long-distance ET up to $\sim 20 \AA$, and the formation of a long-living radical ion pairs have been realised [21]. In only a few successful cases it has been shown that ET remains still effective, within several picoseconds, at $77-10 \mathrm{~K}$ in model porphyrin-A systems $[15,20,21]$ and between porphyrin subunits in artificial triads [44].

A new strategy for the construction of functional supramolecular assemblies generally proposed firstly by Lehn [45] is based on the combination of these two principally different approaches. In this relation, we realised a simple and yet potentially versatile strategy for fabricating highly organised multimolecular tetrapyrrole assemblies in nearly non-polar solvents as well as in polymeric films $[18,44,46-49]$. At the first stage it includes the design and synthesis of precursor molecular blocks such as $\mathrm{Zn}$-porphyrin or $\mathrm{Zn}$ chlorin chemical dimers or trimers where $\pi$-conjugated macrocycles are covalently linked via spacers of various nature $\left(-\mathrm{CH}_{2}-\mathrm{CH}_{2}-\right.$ or a phenyl ring in mesoposition). Additionally, different types of electron acceptors (quinone, anthraquinone, pyromellitimide, $\mathrm{NO}_{2}$ ) may be covalently linked to these dimers by flexible or rigid spacers. At the second stage newly prepared molecular blocks may be self-assembled with pyridyl containing porphyrin or chlorin extra-ligands via non-covalent binding interactions (two-fold extra-ligation effect following the "key-hole" principle). It has been shown that the matching geometry between $\mathrm{N}$ atoms in pyridyl containing extra-ligands and $\mathrm{Zn}$ $\mathrm{Zn}$ distance in the dimers and trimers plays the essential role in the formation of triads and 
pentads with relatively well-defined conformational rigidity [46-48]. In the result, we have succeeded to form distinct arrays of variable structure with a controlled number of electronically interacting chromophores. The alternative principles of the self-assembling of $\mathrm{Zn}$-chlorin aggregates coupled by a covalent link with the bacteriochlorin molecule have also been proposed and realised $[41,50,51]$.

At present, the realisation of the RC-like sequential ET relay or superexchange ET in model multiporphyrin systems remains very difficult with respect to the efficiency of charge separation and the reaction mode. In this respect, the multistep ET strategy in multiporphyrin models containing additional $\mathrm{D}$ and $\mathrm{A}$ seems to be attractive [21,24,32,34]. As it was discussed in Ref. [32], in view of more closer mimicry of the natural ET relay in the $\mathrm{RC}$, the initial ET has to be a charge separation between tetrapyrrole macrocycles followed by a secondary charge transfer (CT) reactions to other $\mathrm{D}$ or $\mathrm{A}$. Known examples of synthetic triads showing this property were analysed in Ref. [32] and were considered to be interesting in relation to the issue of superexchange vs sequential mechanism. At last, as far as the first ET step in natural RC takes place from a chlorophyll dimer to a pheophytin it would be desirable to realise this step in model systems.

In light of these ideas, we have investigated the energy and ET dynamics in self-assembled triads of tetrapyrrole compounds with respect to the experimental detection of the dominant pathways in the non-radiative deactivation of the locally excited states of interacting subunits including possible ET steps dimer $\rightarrow$ monomer $\rightarrow A$. In the first part of the paper we will analyse the dynamies of relaxation processes in $\mathrm{Zn}$-octaethylporphyrin chemical dimers covalently linked via spacers of various nature with electron acceptors such as benzoquinone, anthraquinone and pyromellitimide. In the second part we will concentrate on the energy and ET processes in triads prepared via non-covalent binding interactions of $\mathrm{Zn}$-octaethylporphyrin with dipyridyl containing tetrapyrrole extra-ligands (porphyrin, chlorin, tetrahydroporphyrin). These triads do not contain additional electron acceptors. The third part will be devoted to the comparative studies of the above triads containing electron acceptors covalently linked to the dimer. Especially we like to discuss what ET steps are realised and whether superexchange mechanism can be mimicked and identified in such arrays with well-defined and fixed geometries.

\section{Experimental}

\subsection{Synthetic methods}

Chemical structures of all molecular subunits being used upon formation of the triads (the dimer, electron acceptors and extra-ligands) are shown in Fig. 1. The preparation, identification and purification of the dimer 1,4-bis \{[zinc(II)] $5-(2,3,7,8,12,13,17,18$-octaethylporphyrinyl $)\}$ benzene, have been reported in Ref. [47]. The corresponding model compounds based on the dimer $(\mathrm{ZnOEP})_{2} \mathrm{Ph}$ and electron acceptors para-benzoquinone (Q), pyromellitimide (Pim) and anthraquinone (AQ) were prepared and identified according to procedures described in Refs. $[52,53]$. It is known [32] that Pim is well suited for detection of photoinduced ET kinetics because of the intense characteristic absorption band at $\lambda_{\max }=$ $715 \mathrm{~nm}$ of its anion radical and a pertinent oneelectron reduction potential with respect to our systems. Extra-ligands, dipyridyl substituted porphyrin free bases, $\mathrm{H}_{2} \mathrm{P}(m \hat{\mathrm{P} y r})_{2}$-(iso- $\left.\mathrm{PrPh}\right)_{2}$ and $\mathrm{H}_{2} \mathrm{P}(m \text {-Pyr })_{2}$-(iso- $\left.\mathrm{Pr} \mathrm{Ph}\right)_{2}$, were synthesised and purified according to known methods [54,55]. The two other extra-ligands, free-base chlorin with opposite pyridyls, $\mathrm{H}_{2} \mathrm{Chl}(m-\mathrm{Pyr})_{2}$, and free-base tetrahydroporphyrin with opposite pyridyls, $\mathrm{H}_{2} \mathrm{THP}(m-\mathrm{Pyr})_{2}$, were synthesised and identified according to procedures described in Ref. [56].

The triads were formed at room temperature during a titration of the chemical dimer solution by the extra-ligand solution [47-49]. In order to form the self-aggregated complexes the zinc-porphyrin dimers were diluted in a $10 \times 10 \mathrm{~mm}^{2} \mathrm{ab}-$ sorption cell to concentrations varying between 1 and $3 \times 10^{-6} \mathrm{M}$ in toluene or toluene-methylcyclohexane solutions (Aldrich HPLC grade). In titration experiments a much higher concentrated 


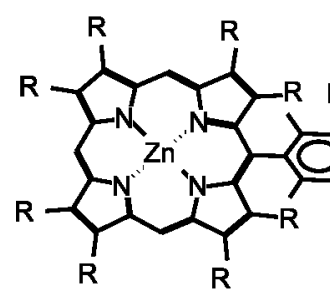

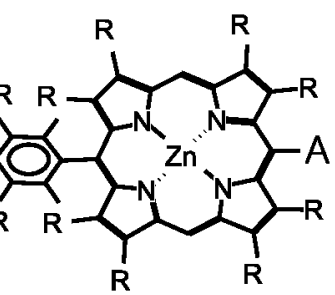

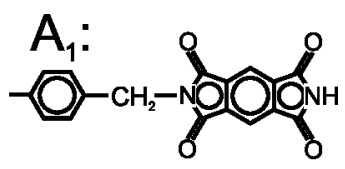<smiles></smiles>

$\mathrm{Zn}(\mathrm{OEP})_{2} \mathrm{Ph}$

R: $\mathrm{C}_{2} \mathrm{H}_{5}$

$A_{3}:$<smiles>Cc1ccccc1OS(=O)(=O)c1ccc(O)c2c1C(=O)c1c(O)cccc1C2=O</smiles><smiles>O=C1c2cccc(c2O)C2(O)c3cccc(c3O)C12</smiles><smiles></smiles>

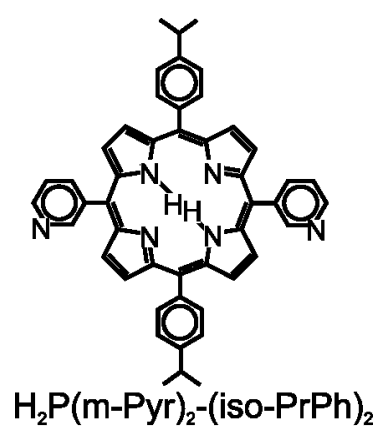

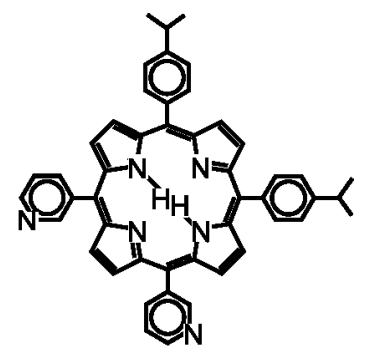

$\mathrm{H}_{2} \mathrm{P}\left(\mathrm{m}^{\wedge} \mathrm{Pyr}\right)_{2}$-(iso-PrPh) ${ }_{2}$

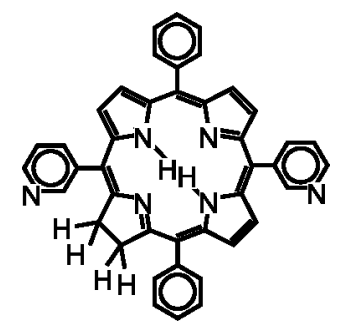

$$
\mathrm{H}_{2} \mathrm{Chl}(\mathrm{m}-\mathrm{Pyr})_{2}
$$

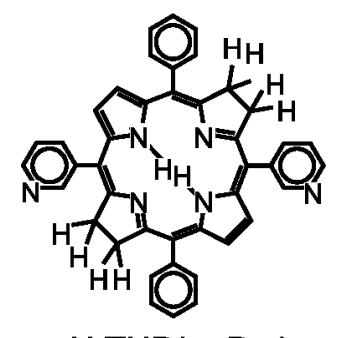

$\mathrm{H}_{2} \mathrm{THP}(\mathrm{m}-\mathrm{Pyr})_{2}$

Fig. 1. Chemical structures of the dimer $(\mathrm{ZnOEP})_{2} \mathrm{Ph}$ with a phenyl spacer and the corresponding subunits being used for triad formation: Additional electron acceptors, para-benzoquinone (Q), pyromellitimide (Pim) and anthraquinone (AQ), linked in 5-mesoposition of the porphyrin ring to the dimer by various spacers that are shown also. Dipyridyl substituted tetrapyrrole extra-ligands: free-base porphyrin with adjacent pyridyls- $-\mathrm{H}_{2} \mathbf{P}\left(m^{\wedge} \mathrm{Pyr}\right)_{2}$-(iso-PrPh $)_{2}$, free-base porphyrin with opposite pyridyls- $\mathrm{H}_{2} \mathbf{P}\left(m^{-}-\mathrm{Pyr}\right)_{2}-$ (iso-PrPh $)_{2}$, free-base chlorin with opposite pyridyls $-\mathrm{H}_{2} \mathrm{Chl}(m \text {-Pyr })_{2}$, free-base tetrahydroporphyrin with opposite pyridyls $-\mathrm{H}_{2} \mathrm{THP}(m-\mathrm{Pyr})_{2}$.

$\left(\approx 2 \times 10^{-5} \mathrm{M}\right)$ solutions of the desired dipyridyl substituted tetrapyrrole extra-ligands were added to this cell in steps of $10 \mu \mathrm{l}$. The titration was finished, when the same concentration as for the zinc-porphyrin dimer was reached, and no further changes in absorption of the dimer were detected 
Table 1

Complexation constants, $K_{\mathrm{C}}$ for triads containing the chemical dimer ( $\mathrm{ZnOEP})_{2} \mathrm{Ph}$ and various extra-ligands (toluene, $293 \mathrm{~K}$ )

\begin{tabular}{lll}
\hline No & Triad & $K_{\mathrm{C}}\left(\mathrm{M}^{-1}\right)$ \\
\hline 1 & $(\mathrm{ZnOEP})_{2} \mathrm{Ph} \otimes \mathrm{H}_{2} \mathrm{P}\left(m^{\wedge} \mathrm{Pyr}\right)_{2}$-(iso-PrPh $)_{2}$ & $1.7 \times 10^{7}$ \\
2 & $(\mathrm{ZnOEP})_{2} \mathrm{Ph} \otimes \mathrm{H}_{2} \mathrm{P}(m-\mathrm{Pyr})_{2}$-(iso-PrPh $)_{2}$ & $1.1 \times 10^{6}$ \\
3 & $(\mathrm{ZnOEP})_{2} \mathrm{Ph} \otimes \mathrm{H}_{2} \mathrm{Chl}(m \text {-Pyr })_{2}$ & $1.7 \times 10^{6}$ \\
4 & $(\mathrm{ZnOEP})_{2} \mathrm{Ph} \otimes \mathrm{H}_{2} \mathrm{THP}(m-\mathrm{Pyr})_{2}$ & $3.0 \times 10^{6}$ \\
\hline
\end{tabular}

Absorption and fluorescence (excited at the isosbestic point, $\lambda_{\mathrm{ex}}=545 \mathrm{~nm}$ ) spectra have been measured after each step of the titration procedure and then have been used for the calculation of the complexation constants according to the method described in Ref. [47]. The strength of complexation depends strongly on matching of the $\mathrm{Zn}-\mathrm{Zn}$ distance in the dimer to the $\mathrm{N}-\mathrm{N}$ distance of the pyridyl substituents (Fig. 2) being maximal for $\mathrm{H}_{2} \mathrm{P}\left(m^{\wedge} \mathrm{Pyr}\right)_{2}$-(iso-PrPh $)_{2}$ case.

within experimental error. Absorption and fluorescence spectra were measured after each step of the titration procedure and used for the calculation of the complexation constants (Table 1). The corresponding association constants obtained for self-assembled triads are of $K_{\mathrm{C}} \sim 10^{6}-10^{7} \mathrm{M}^{-1}$ being significantly higher with respect to those found for the dipyridinated dimer $(\mathrm{ZnOEP})_{2} \mathrm{Ph}$ $\left(K_{\mathrm{C}}=1.5 \times 10^{4} \mathrm{M}^{-1}\right.$ [47]). The optimised structures of triads (HyperChem software, release 4, semi-empirical method PM3) are presented in Fig. 2. It is seen from Fig. 2 that in all cases the selfassembly is realised via the selective two-fold extra-coordination of $\mathrm{Zn}$-porphyrin dimer and the ligand thus leading to high complexation constants.

\subsection{Spectral and kinetic measurements}

Absorption spectra were recorded on a standard absorption spectrometer Shimadzu UV3101PC. Steady state fluorescence measurements were measured on a Shimadzu RF340 spectrometer. Fluorescence time-resolved spectra of the triads have been detected using laboratory laser picosecond fluorescent setup with 2-D (wavelength-time) registration. The excitation source is based on a dye laser (Spectra Physics Model 375), synchronously pumped by an Ar-laser (Spectra Physics Model 171, repetition rate $4 \mathrm{MHz}, 10 \mathrm{ps}$ laser pulses), and the detection system is based on a Streak-Scope (Hamamatsu Model C4334, system response $\Delta_{1 / 2} \approx 30 \mathrm{ps}$ in the 1-ns range of a StreakScope). In order to analyse fluorescence multicomponent kinetics time correlated single photon counting (TCSPC) experiments were performed. A vertical polarised dye laser (Spectra $\mathrm{Ar}^{+}$-Laser Mod. 171/Dye-Laser Mod. 343, repetition rate of 4 $\mathrm{MHz}$, pulses of 15 ps FWHM) was used for excitation. The fluorescence was detected under magic angle $\left(54.7^{\circ}\right)$ through a minimonochromator by a micro-channel plate. The system response was $\Delta t_{1 / 2}=75$ ps. Fluorescence detection was done multiple at 12 different wavelengths covering a range from 570 to $750 \mathrm{~nm}$ in order to obtain amplitude spectra. The fit of the amplitude decay was performed with three times for each data set using global analysis based on a commercial Globals Unlimited software program. Experiments on triads were performed in solutions containing a 1:1 mixture of the dimer and corresponding extra-ligand. On the basis of complexation constants $K_{\mathrm{C}}$ obtained for the corresponding triads (Table 1) and initial concentrations of reactants, the contents of complexed and uncomplexed components were calculated in every experiment in order to fix the longest time component appropriately.

Pump probe measurements were carried out using higher concentrated solutions $\left(5 \times 10^{-5} \mathrm{M}\right)$ prepared by one-step mixing of the necessary volumes of two solutions with known concentrations of the dimer and extra-ligand according to the desired ratio (usually 1:1). For the pumpprobe experiments a regenerative amplifier system (Quantronix 4800 Series, Ti:Sa regenerative amplifier, $1 \mathrm{kHz}$ ) driven by a Coherent Mira 900B Ti:Si laser was used to generate the pump wavelength in an optic parametric amplifier (TOPAS). The wavelength could be tuned from 400 to 800 $\mathrm{nm}$. The probe wavelength was generated in a quartz plate as a supercontinuum ranging from $450 \mathrm{~nm}$ to the near IR. Pump and probe-beam transmit the sample under the magic angle $\left(54.7^{\circ}\right)$. The experimental response was $\Delta t_{1 / 2} \sim 280 \mathrm{fs}$. The kinetics were deconvoluted and fitted using the Marquardt algorithm [57]. The details of the experimental setup have been described by us recently [44]. Time-resolved TCSPC and pump probe experiments were performed in a homemade quartz cell equipped with a mini-motor for 
I
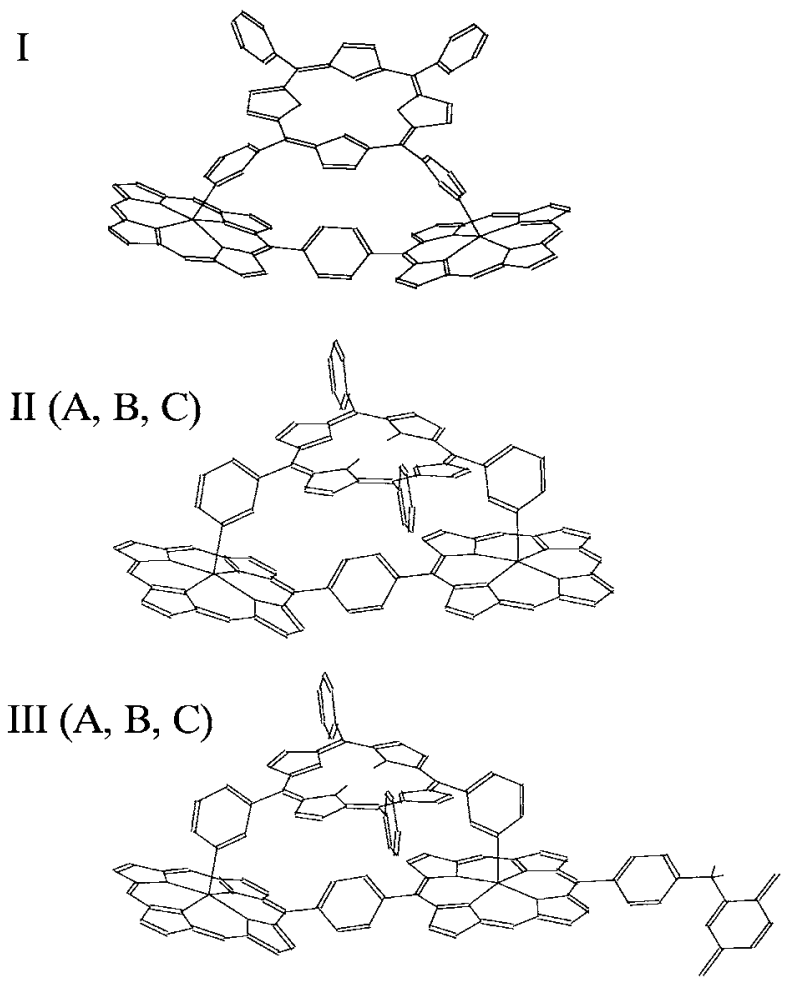

IV

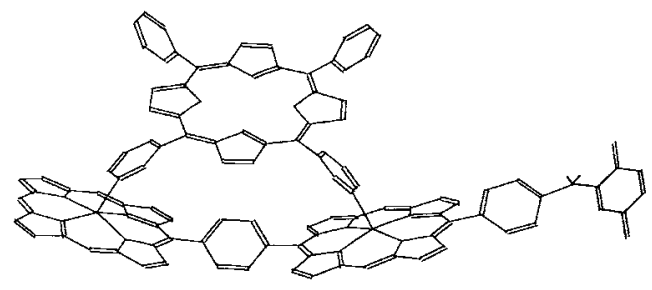

\section{V}

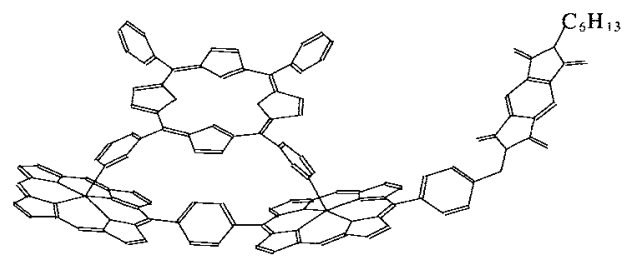

Fig. 2. Mutual arrangement of the interacting subunits in triads without (I, II) and with (III-V) electron acceptors (HyperChem software package, release 4, semiempirical method PM3). For clarity, side alkyl substituents in pyrrole and phenyl rings are omitted. I: $(\mathrm{ZnOEP})_{2} \mathrm{Ph} \otimes \mathrm{H}_{2} \mathrm{P}\left(m^{\wedge} \mathrm{Pyr}\right)_{2}$-(iso-PrPh$)_{2} ; \mathrm{II}$, triads of the same geometry but with various extra-ligands: (A) $(\mathrm{ZnOEP})_{2} \mathrm{Ph} \otimes \mathrm{H}_{2} \mathrm{P}$ $(m-\mathrm{Pyr})_{2}$-(iso-PrPh $)_{2}$, (B) $(\mathrm{ZnOEP})_{2} \mathrm{Ph} \otimes \mathrm{H}_{2} \mathrm{Chl}(m-\mathrm{Pyr})_{2}$ and (C) $(\mathrm{ZnOEP})_{2} \mathrm{Ph} \otimes \mathrm{H}_{2} \mathrm{THP}(m-\mathrm{Pyr})_{2}$; III, triads having the same geometry and electron acceptor (quinone) but different extra-ligands: (A) $\mathrm{ZnOEP}_{2} \mathrm{Ph}-\mathrm{Q} \otimes \mathrm{H}_{2} \mathrm{P}(m-\mathrm{Pyr})_{2}$-(iso-PrPh $)_{2}$, (B) ( $\left.\mathrm{ZnOEP}\right)_{2} \mathrm{Ph}-$ $\mathrm{Q} \otimes \mathrm{H}_{2} \mathrm{Chl}(m-\mathrm{Pyr})_{2}$ and $(\mathrm{C})(\mathrm{ZnOEP})_{2} \mathrm{Ph}-\mathrm{Q} \otimes \mathrm{H}_{2} \mathrm{THP}(m-\mathrm{Pyr})_{2} ; \quad \mathrm{IV}:(\mathrm{ZnOEP})_{2} \mathrm{Ph}-\mathrm{Q} \otimes \mathrm{H}_{2} \mathrm{P}\left(m^{\wedge} \mathrm{Pyr}\right)_{2}-(\text { iso-PrPh })_{2} ; \quad \mathrm{V}: \quad(\mathrm{ZnOEP})_{2} \mathrm{Ph}-$ $\mathrm{Pim} \otimes \mathrm{H}_{2} \mathrm{P}\left(m^{\wedge} \mathrm{Pyr}\right)_{2}$-(iso- $\left.\mathrm{PrPh}\right)_{2}$. 
the solution circulation (volume of $9 \mathrm{ml}$ ) in order to avoid artefacts caused by a possible photodecomposition of the compounds. The possible manifestation of multiphoton effects during fs pump-probe measurements has been tested by the variation of the energy of the pumping pulse. The spinning frequency was chosen to have a fresh excitation volume for each pump pulse (i.e. every 1 $\mathrm{ms}$ ) as well as the whole relaxation of excited states took place before the following exciting pulse.

\section{Results and discussion}

\subsection{Electron transfer in covalently linked $(\mathrm{ZnOEP})_{2} \mathrm{Ph}-\mathrm{A}$ systems}

At $293 \mathrm{~K}$ in toluene, static measurements reveal that for all $(\mathrm{ZnOEP})_{2} \mathrm{Ph}-\mathrm{A}$ systems under consid- eration absorption spectra in the range of the dimer Soret and Q-bands are identical with that obtained for pure dimer, such as shown for other A-containing porphyrins with neutral spacers $[32,37]$. It means that the ground-state interactions between the dimer and attached acceptors are absent. Table 2 summarises structural and photophysical parameters as well as the calculated energies of the hypothetical radical ion pair states and Gibbs free energies of ET reaction for these systems. In order to use some of them as appropriate candidates for including in triads, we will first compare the dynamics of ET processes.

$(\mathrm{ZnOEP})_{2} P h-A_{1}$ system: In contrast to the pure dimer $(\mathrm{ZnOEP})_{2} \mathrm{Ph}$ (fluorescence decay $\tau_{\mathrm{S}}^{0}=1.21$ ns in toluene at $293 \mathrm{~K}$ ), essential fluorescence quenching is observed $\left(\tau_{\mathrm{S}}=135 \mathrm{ps}\right.$, Table 2$)$. This quenching becomes stronger $\left(\tau_{\mathrm{S}}=54 \mathrm{ps}\right)$ for pyridynated complexes of the dimer (Fig. 3).

Table 2

Structural and photophysical parameters for covalently linked $(\mathrm{ZnOEP})_{2} \mathrm{Ph}-\mathrm{A}$ systems in toluene at room temperature

\begin{tabular}{lllllllll}
\hline System $^{\text {a }}$ & $E\left(\mathrm{~S}_{1}^{\mathrm{D}}\right)^{\mathrm{b}}(\mathrm{eV})$ & $E_{\mathrm{A}}^{\mathrm{redc}}(\mathrm{eV})$ & $r_{\mathrm{A}}{ }^{\mathrm{d}}(\AA)$ & $r_{\mathrm{DA}}{ }^{\mathrm{e}}(\AA)$ & $E(\mathrm{IP})^{\mathrm{f}}(\mathrm{eV})$ & $\Delta G^{0 \mathrm{~g}}(\mathrm{eV})$ & $\tau_{\mathrm{S}}(\mathrm{ps})$ & $k_{\mathrm{ET}} \times 10^{10} \mathrm{~s}^{-1 \mathrm{~h}}$ \\
\hline$(\mathrm{ZnOEP})_{2} \mathrm{Ph}-\mathrm{A}_{1}$ & 2.13 & -0.76 & 3.5 & 13.0 & 2.00 & -0.13 & $135^{\mathrm{i}}$ & 0.66 \\
$(\mathrm{ZnOEP})_{2} \mathrm{Ph}-\mathrm{A}_{2}$ & 2.13 & -0.45 & 3.3 & 10.8 & 1.72 & -0.41 & $34^{\mathrm{i}}$ & 2.86 \\
$(\mathrm{ZnOEP})_{2} \mathrm{Ph}-\mathrm{A}_{3}$ & 2.13 & -0.86 & 3.9 & 8.7 & 1.90 & -0.23 & $1240^{\mathrm{j}}$ & $\ll 0.08$ \\
$(\mathrm{ZnOEP})_{2} \mathrm{Ph}-\mathrm{A}_{4}$ & 2.13 & -0.86 & 3.9 & 15.0 & 2.03 & -0.10 & $870^{\mathrm{j}}$ & 0.03 \\
$(\mathrm{ZnOEP})_{2} \mathrm{Ph}-\mathrm{A}_{5}$ & 2.13 & -0.86 & 3.9 & $10.4-4.0$ & $\sim 1.96$ & $\sim-0.17^{\mathrm{k}}$ & $5-40^{\mathrm{l}}$ & $19.9-2.4$ \\
\hline
\end{tabular}

\footnotetext{
${ }^{\mathrm{a}}$ The structures of $\mathrm{A}_{1}, \mathrm{~A}_{2}, \mathrm{~A}_{3}, \mathrm{~A}_{4}, \mathrm{~A}_{5}$ and corresponding spacers are shown in Fig. 1.

${ }^{b}$ The energy level of the dimer locally excited $S_{1}$-state was determined on the basis of the corresponding fluorescence and absorption $\mathrm{Q}(0,0)$ bands.

${ }^{\circ}$ One electron reduction potentials $E_{1 / 2}^{\text {red }}$ (in dimethylformamide, DMF, vs SCE) were taken for Pim from Ref. [32], for Q and AQ from Ref. [58]. One electron oxidation potential for the dimer $(\mathrm{ZnOEP})_{2} \mathrm{Ph}$ was used to be $E_{1 / 2}^{\mathrm{ox}}=0.74 \mathrm{~V}$ taking into account the value of $E_{1 / 2}^{\mathrm{ox}}=0.63 \mathrm{~V}$ (in DMF vs SCE [59]) and the fact that the supporting electrolyte tetrabutylammonium perchlorate being coordinated to the porphyrin central $\mathrm{Zn}$ ion lowers the first oxidation potential by $0.11 \mathrm{~V}$ [60].

${ }^{\mathrm{d}}$ Acceptor $r_{\mathrm{A}}$ radii for Pim and Q were taken from Ref. [61] and for AQ from Ref. [62]. Donor radius $r_{\mathrm{A}}=5.5 \AA$ [61].

${ }^{\mathrm{e}}$ Intercenter distances $r_{\mathrm{DA}}$ were taken for $(\mathrm{ZnOEP})_{2} \mathrm{Ph}-\mathrm{A}_{1}$ from Ref. [32], for other systems were estimated on the basis of Draiding structural models and molecular modeling (HyperChem software package, release 4, semiempirical method PM3) taking into account possible steric interactions.

${ }^{f}$ The energy levels of the ion pair states in toluene were estimated by $[63,64]: E(\mathrm{IP})=e\left(E_{\mathrm{D}}^{\mathrm{ox}}-E_{\mathrm{A}}^{\mathrm{red}}\right)+\Delta G_{\mathrm{S}}, \Delta G_{\mathrm{S}}=$ $\frac{e^{2}}{4 \pi \varepsilon_{0}}\left[\left(\frac{1}{2 r_{\mathrm{D}}}+\frac{1}{2 r_{\mathrm{A}}}-\frac{1}{r_{\mathrm{DA}}}\right) \frac{1}{\varepsilon}-\left(\frac{1}{2 r_{\mathrm{D}}} \frac{1}{\varepsilon_{\mathrm{D}}^{\prime}}+\frac{1}{2 r_{\mathrm{A}}} \frac{1}{\varepsilon_{\mathrm{A}}^{\prime}}\right)\right]$, where dielectric constants are $\varepsilon$ (toluene $)=2.38$ or $\varepsilon$ (methylcyclohexane) $=2.02$ [58], and $\varepsilon_{\mathrm{A}}=\varepsilon_{\mathrm{D}}=36.7$ (DMF [58], where $E_{1 / 2}^{\mathrm{red}}$ and $E_{1 / 2}^{\mathrm{ox}}$ were measured). The term $\Delta G_{\mathrm{S}}$ corrects the effects of solvent polarity as well as the Coulombic stabilisation energy between the charged donor and acceptor.

${ }^{\mathrm{g}}$ Gibbs free energy of ET reaction was calculated according to Ref. [63] $\Delta G^{0}=e\left(E_{\mathrm{D}}^{\mathrm{ox}}-E_{\mathrm{A}}^{\mathrm{red}}\right)+\Delta G_{\mathrm{S}}-E\left(\mathrm{~S}_{1}^{\mathrm{D}}\right)$.

${ }^{\mathrm{h}} \mathrm{ET}$ rate constants $k_{\mathrm{ET}}$ were calculated using the formulae $k_{\mathrm{ET}}=1 / \tau_{\mathrm{S}}-1 / \tau_{\mathrm{S}}^{0}$, where $\tau_{\mathrm{S}}^{0}=1.21 \mathrm{~ns}$ (TCSPC) is the fluorescence decay of pure dimer $(\mathrm{ZnOEP})_{2} \mathrm{Ph}$ in toluene, $\tau_{\mathrm{S}}$ is the $\mathrm{S}_{1}$-state decay measured for $(\mathrm{ZnOEP})_{2} \mathrm{Ph}-\mathrm{A}$ systems.

${ }^{\mathrm{i}}$ TCSPC measurements in toluene.

i Pump-probe measurements in methylcyclohexane.

${ }^{\mathrm{k}} E(\mathrm{IP})$ and $\Delta G^{0}$ values are roughly estimated because of uncertainty of intercenter distances $r_{\mathrm{DA}}$ in this system.

${ }^{\mathrm{I}}$ Decay is multiexponential because of a spacer flexibility, the estimated limits are presented.
} 


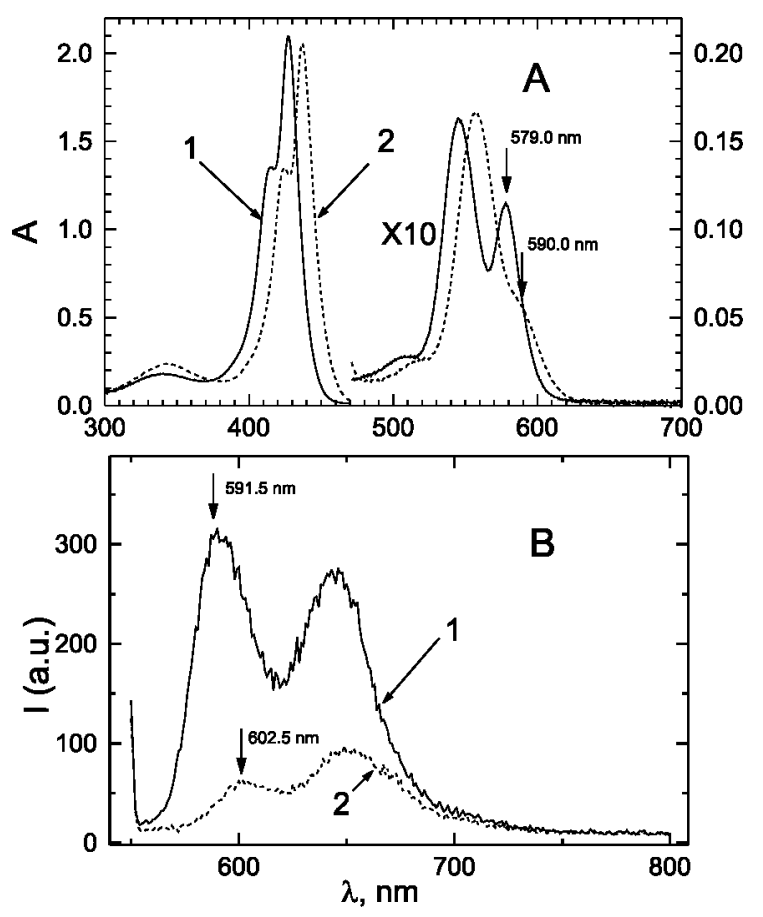

Fig. 3. Absorption (A) and fluorescence $\left(B, \lambda_{\mathrm{ex}}=545 \mathrm{~nm}\right)$ spectra of $(\mathrm{ZnOEP})_{2} \mathrm{Ph}-\mathrm{A}_{1}$ in (1) toluene and (2) toluene/pyridine solutions. The splitting of the Soret band is due to excitonic interactions in the dimer $[26,29,47]$. Spectral shifts and $\mathrm{Q}(0,0)$ band shapes are typical for the pyridine-ligated dimer $(\mathrm{ZnOEP})_{2} \mathrm{Ph}$ [47] but the fluorescence decrease is characteristic for the Pim containing dimer only.

Femtosecond transient absorption spectra show a noticeable spectral dynamics (Fig. 4). The rising absorption near $670 \mathrm{~nm}$ and $715 \mathrm{~nm}$ can be ascribed to $\mathrm{ZnP}^{+}[21,65]$ and $\mathrm{Pim}^{-}[32,61]$, respectively. Transient absorption decays measured at 670 and $715 \mathrm{~nm}$ coincide within experimental error (Fig. 5) manifesting the existence of an one-step ET from the dimer $S_{1}$-state to Pim. Fig. 5 also shows that the addition of pyridine to toluene solutions accelerates the formation of CT-state reflecting the same tendency observed for various covalently linked Zn-porphyrin-A systems [60,70]. Data presented in Table 2 and Fig. 5 indicate a reasonable agreement between values obtained by TCSPC method and a pump-probe technique.

$(\mathrm{ZnOEP})_{2} \mathrm{Ph}-\mathrm{A}_{2}$ System: Like in the previous case, transient absorption changes in the region near $670-680 \mathrm{~nm}$ may be attributed to $\mathrm{Zn} \mathrm{P}^{+}$. At

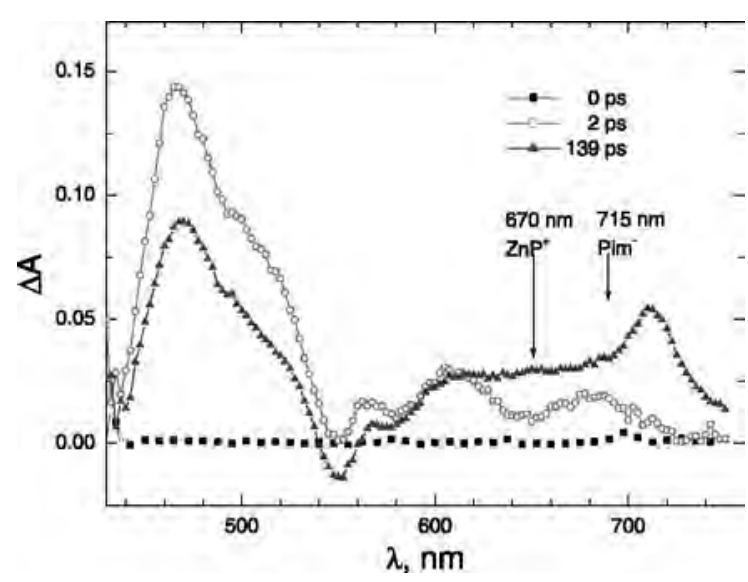

Fig. 4. Time-resolved absorption spectra of $(\mathrm{ZnOEP})_{2} \mathrm{Ph}-\mathrm{A}_{1}$ at delay times 0,2 and $139 \mathrm{ps}$ (toluene, $\lambda_{\text {pump }}=540 \mathrm{~nm}$ ).

$293 \mathrm{~K}$, the decay value derived from the time evolution of the transient absorbance at $680 \mathrm{~nm}$ corresponds to the dimer $S_{1}$-state deactivation within a time of $\tau_{\mathrm{S}}=25 \mathrm{ps}$ in toluene and $17.6 \mathrm{ps}$ in toluene/acetone mixture (1:1). According to TCSPC measurements $\tau_{\mathrm{S}}=34 \mathrm{ps}$ in toluene (Table 2) and $27 \mathrm{ps}$ in toluene/pyridine at the same temperature. In fact, the photoinduced ET in $(\mathrm{ZnOEP})_{2} \mathrm{Ph}-\mathrm{A}_{2}$ resembles the same features observed for $(\mathrm{ZnOEP})_{2} \mathrm{Ph}-\mathrm{A}_{1}$, but with higher rate constants.

$(\mathrm{ZnOEP})_{2} \mathrm{Ph}-\mathrm{A}_{3},(\mathrm{ZnOEP})_{2} \mathrm{Ph}-\mathrm{A}_{4}$ and $\left.\mathrm{ZnOEP}\right)_{2}$ $P h-A_{5}$ Systems: It is seen from Fig. 1 that in these $\mathrm{D}-\mathrm{A}$ pairs the dimer $(\mathrm{ZnOEP})_{2} \mathrm{Ph}$ and acceptor, $A Q$ are the same. The two first AQ-substituted dimers have relatively rigid spacers but differ by fixed center-to-center distances $r_{\mathrm{DA}}: r_{\mathrm{DA}}\left(\mathrm{A}_{3}\right)<r_{\mathrm{DA}}$ $\left(\mathrm{A}_{4}\right)$ (see Table 2). In the last system $(\mathrm{ZnOEP})_{2} \mathrm{Ph}$ $\mathrm{A}_{5}$, the spacer is longer with respect to those for the former two dimers. Nevertheless, because of its flexibility the realised $r_{\mathrm{DA}}$ distances are not so long and may vary depending additionally on steric interactions. Correspondingly, the degree of electronic interaction between the same D and $\mathrm{A}$ has to be different in the three AQ-substituted dimers as is manifested in the variation of ET experimental rate constants.

It follows from Table 2 that for $(\mathrm{ZnOEP})_{2}$ $\mathrm{Ph}-\mathrm{A}_{3}$ with the smallest $r_{\mathrm{DA}}=8.7 \mathrm{~A}$ the dimer $\mathrm{S}_{1}$ state quenching is not observed in methylcyclohexane at $293 \mathrm{~K}$. However, the increase of the 
A

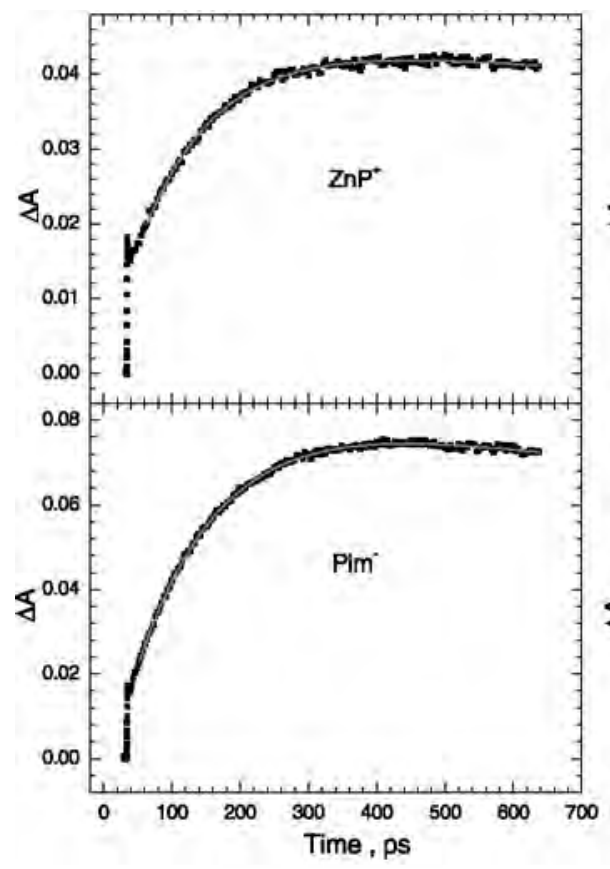

B

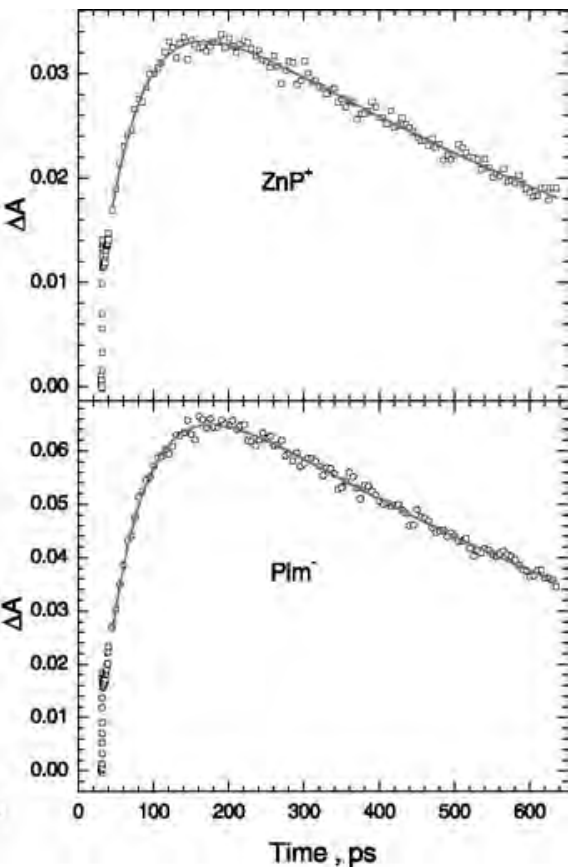

Fig. 5. Time evolution of the transient absorbance for $(\mathrm{ZnOEP})_{2} \mathrm{Ph}-\mathrm{A}_{1}$ in $(\mathrm{A})$ toluene and $(\mathrm{B})$ toluene/pyridine at $293 \mathrm{~K}$ formed by the excitation at $\lambda_{\text {pump }}=540 \mathrm{~nm}$ and measured at $670 \mathrm{~nm}\left(\mathrm{ZnP}^{+}\right)$and $715 \mathrm{~nm}\left(\right.$ Pim $\left.^{-}\right)$. Two-exponential fit $I(t)=A_{1} \exp \left(-t / \tau_{1}\right)+$ $A_{2} \exp \left(-t / \tau_{2}\right)+\delta(t)$ gives the following: $\tau_{1}=111$ ps $\left(A_{1}=-0.033\right), \tau_{2}=6037$ ps $\left(A_{2}=0.046\right)$ for $\mathrm{ZnP}^{+}$and $\tau_{1}=126$ ps $\left(A_{1}=-0.073\right), \tau_{2}=3435$ ps $\left(A_{2}=0.087\right)$ for $\mathrm{Pim}^{-}$in toluene; $\tau_{1}=52.9 \mathrm{ps}\left(A_{1}=-0.033\right), \tau_{2}=1078 \mathrm{ps}\left(A_{2}=0.056\right)$ for $\mathrm{ZnP}^{+}$and $\tau_{1}=54.3 \mathrm{ps}\left(A_{1}=-0.073\right)$ and $\tau_{2}=914 \mathrm{ps}\left(A_{2}=0.102\right)$ for $\mathrm{Pim}^{-}$in toluene/pyridine. The short component is connected with a charge separation, the long component reflects a charge recombination process.

solvent polarity results in significant fluorescence quenching (Fig. 6), and $\tau_{\mathrm{S}}=3.2 \mathrm{ps}$ in pure acetone at room temperature. In fact, these results reflect ET nature of the observed quenching. It is interesting to note that in the second system $(\mathrm{ZnOEP})_{2} \mathrm{Ph}-\mathrm{A}_{4}$ with a larger $r_{\mathrm{DA}}=15.0 \AA$ a noticeable decay shortening of the dimer $S_{1}$-state is still observed in methylcyclohexane at $293 \mathrm{~K}$ even (Table 2) being increased also upon the solvent polarity rise. At last, for $(\mathrm{ZnOEP})_{2} \mathrm{Ph}-\mathrm{A}_{5} \mathrm{~S}_{1}$-state decay of the dimer is multiexponential with the variation of time components from 5 to $\sim 40 \mathrm{ps}$ in methylcyclohexane at $293 \mathrm{~K}$.

We will have to analyse first the results obtained for pyromellitimide- and quinone-substituted dimers, $(\mathrm{ZnOEP})_{2} \mathrm{Ph}-\mathrm{A}_{1}$ and $(\mathrm{ZnOEP})_{2} \mathrm{Ph}-\mathrm{A}_{2}$, having the same geometry but different acceptors. At high temperatures, the semi-classical Marcus theory of endergonic or moderately exergonic non- adiabatic ET occurring within the "normal" region predicts the following expressions for the rate constant $k_{\mathrm{ET}}[66]$ :

$k_{\mathrm{ET}}^{\mathrm{S}}=\frac{2 \pi}{\hbar} \frac{V^{2}}{\left(4 \pi \lambda k_{B} T\right)^{1 / 2}} \exp \left(-\frac{\Delta G^{*}}{k_{\mathrm{B}} T}\right)$

with

$\Delta G^{*}=\frac{\left(\Delta G^{0}+\lambda\right)^{2}}{4 \lambda}$.

Here $k_{\mathrm{B}}$ is Boltzman's constant, $T$ is the temperature, $h$ is Plank's constant, $V$ is the electronic coupling term between the electronic wave functions of the reactant and product states, $\lambda=\lambda_{\text {in }}+\lambda_{\text {ext }}$ is the Gibbs reorganisation energy determined by the nuclear $\lambda_{\text {in }}$ and solvent $\lambda_{\text {ext }}$ reorganisation energies, $\Delta G^{0}$ is the Gibbs free energy of the ET reaction, $\Delta G^{*}$ is the Marcus Gibbs activation energy. For porphyrin macrocycles, the 

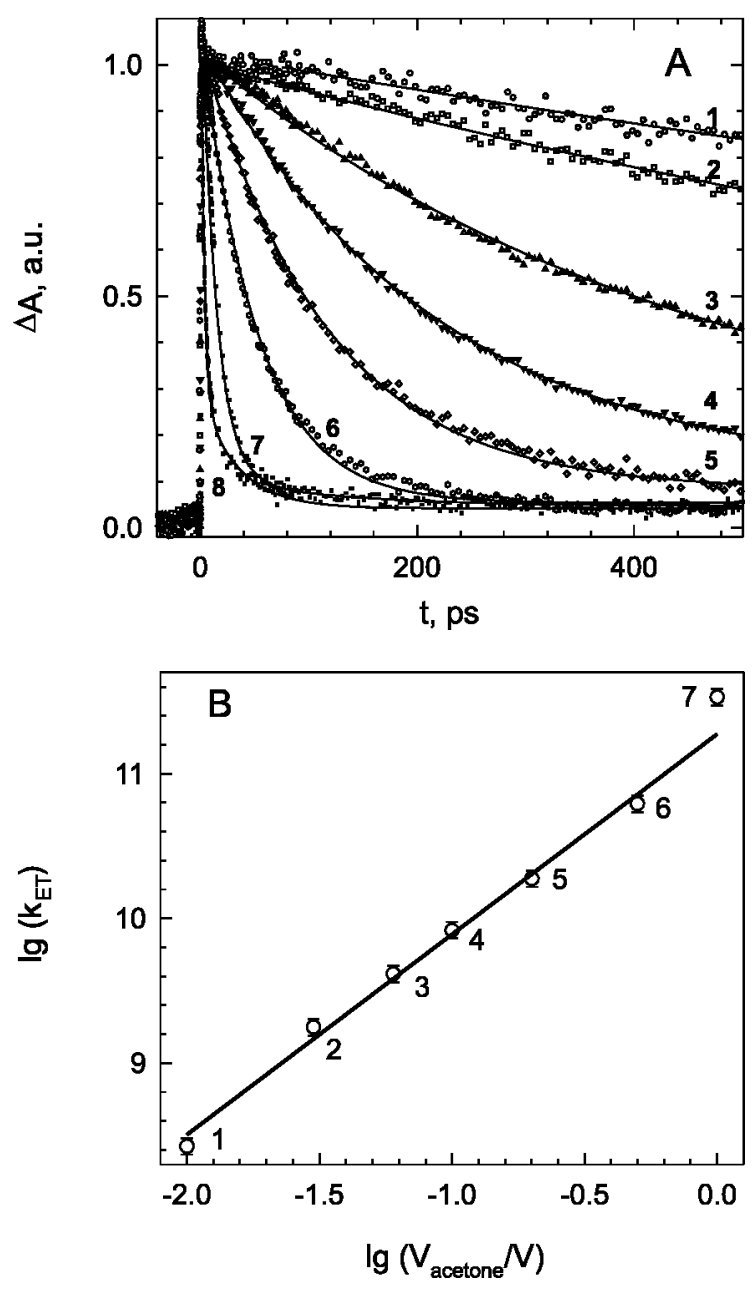

Fig. 6. Time evolution of the transient absorbance (A) and ET rate constant $(\mathrm{B})$ for $(\mathrm{ZnOEP})_{2} \mathrm{Ph}-\mathrm{A}_{3}$ in methylcyclohexaneacetone mixtures on acetone volume content: (1) $0 \%$, (2) $1 \%$, (3) $3 \%$, (4) $6 \%$, (5) $10 \%$, (6) $50 \%$, , (7) $100 \%$. $\lambda_{\text {pump }}=400 \mathrm{~nm}$, $\lambda_{\text {probe }}=620 \mathrm{~nm}, 293 \mathrm{~K}$.

term, $\lambda_{\text {in }}$, involving vibrational energy changes between the reactant and product states was estimated to be $\lambda_{\text {in }} \approx 0.3 \mathrm{eV}[24,67]$.

The solvent-dependent term $\lambda_{\text {ext }}$ for the surrounding medium treated as a dielectric continuum, is expressed as $[24,62,66]$ :

$\lambda_{\text {solv }}=\frac{e^{2}}{4 \pi \varepsilon_{0}}\left[\frac{1}{2 r_{\mathrm{D}}}+\frac{1}{2 r_{\mathrm{A}}}-\frac{1}{r_{\mathrm{DA}}}\right]\left[\frac{1}{\varepsilon_{\mathrm{op}}}-\frac{1}{\varepsilon_{\mathrm{st}}}\right]$

where $r_{\mathrm{D}}$ and $r_{\mathrm{A}}$ are $\mathrm{D}$ and $\mathrm{A}$ radii, respectively, $\varepsilon_{\mathrm{op}}=n^{2}$ is the optical dielectric constant, $n$ is the refraction index and $\varepsilon_{s t}$ is the static dielectric constant of the solvent.

It has been shown [37] that the analysis of the experimental dependence of $k_{\mathrm{ET}}$ on temperature allows to estimate the nuclear factor $\lambda$ and the electronic coupling term $V$ using a modified form of Eq. (1) with the assumption that both $\Delta G^{0}$ and $\lambda$ are temperature independent

$$
\begin{aligned}
& \ln \left[k_{\mathrm{ET}}(\lambda T)^{1 / 2}\right]=C_{2}-\frac{\Delta G^{*}}{k_{\mathrm{B}} T}, \text { where } \\
& C_{2}=\ln \left[\frac{4 \pi^{2}}{h} \frac{V^{2}}{\left(4 \pi k_{\mathrm{B}}\right)^{1 / 2}}\right] .
\end{aligned}
$$

Using this approach we carried out TCSPC experiments for $(\mathrm{ZnOEP})_{2} \mathrm{Ph}-\mathrm{A}_{1}$ in toluene and toluene/pyridine in a temperature range of 273-196 K. Fig. 7 shows that the data for both solvents fall on linear plots. Estimated nuclear and electronic factors are as follows: $\lambda=0.343 \mathrm{eV}, V=1.18 \mathrm{meV}$ (toluene) and $\lambda=0.417 \mathrm{eV}, V=2.12 \mathrm{meV}$ (toluene/pyridine). Taking into account that nuclear factors $\lambda$ do not differ significantly for the two systems of the same geometry, $(\mathrm{ZnOEP})_{2} \mathrm{Ph}-\mathrm{A}_{1}$ and $(\mathrm{ZnOEP})_{2} \mathrm{Ph}-\mathrm{A}_{2}$, and using different values of $\Delta G^{0}$ (Table 2) we obtain the corresponding values of the electronic coupling for the quinone-substi-

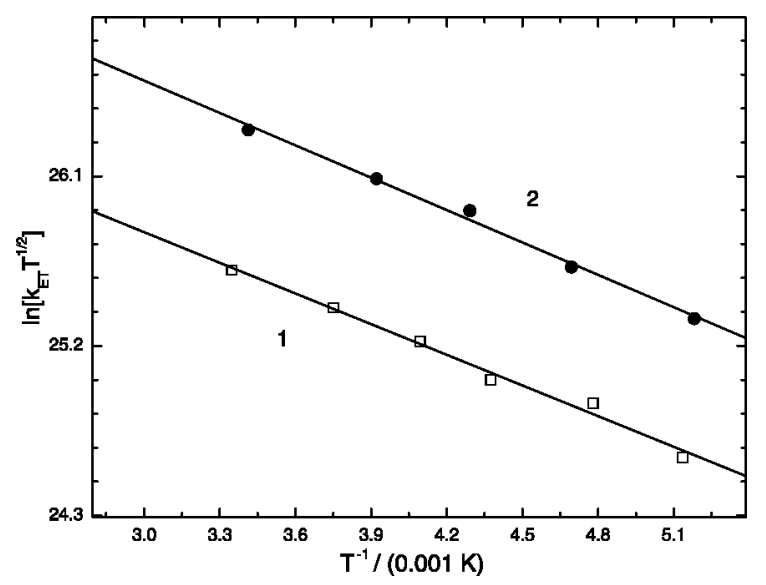

Fig. 7. Marcus analysis of the temperature dependence of $k_{\mathrm{ET}}$ for $(\mathrm{ZnOEP})_{2} \mathrm{Ph}-\mathrm{A}_{1}$ in toluene (1) and toluene/pyridine 150:1 (2) using the approach developed in Ref. [37] (Eq. (4)). Experimental dependencies are fitted by a linear function $y=m x+y_{0}$, where $y_{0}=\ln \left(\left(2 \pi V^{2} / \mathrm{h}\right) \sqrt{\pi / \lambda k_{\mathrm{B}}}\right)$ and $m=-\left(\Delta G^{0}+\lambda\right)^{2} / 4 \lambda k_{\mathrm{B}}$. 
tuted dimer: $V=2.35 \mathrm{meV}$ (toluene) and $V=4.22$ $\mathrm{meV}$ (toluene/pyridine).

It is known [21], that ET reactions are nonadiabatic by the Landau-Zener criteria if they satisfy the following relationship

$4 \pi^{2} V^{2} / h \omega\left(2 \lambda k_{\mathrm{B}} T\right)^{1 / 2}<1$,

where $\omega \sim 100 \mathrm{~cm}^{-1}$ for typical low-frequency solvent motions at $300 \mathrm{~K}$. It follows from the above presented data that for $(\mathrm{ZnOEP})_{2} \mathrm{Ph}-\mathrm{A}_{1}$ and $(\mathrm{ZnOEP})_{2} \mathrm{Ph}-\mathrm{A}_{2}$ this criteria is valid in both solvents. Thus, assuming realistic errors for $\lambda$ and $\Delta G^{0}$ we conclude that at $293 \mathrm{~K}$ the dimer $\mathrm{S}_{1}$-state quenching is due to a non-adiabatic ET. The rise of this quenching for both systems in toluene/ pyridine with respect to that for toluene is due to the fact that the coordination of the porphyrin central $\mathrm{Zn}$ ion with pyridine lowers the first oxidation potential by $0.11 \mathrm{~V}[60]$ thus leading to the increase of $\Delta G^{0}$ for the ET reaction. In the case of pyromellitimide-substituted dimer $(\mathrm{ZnOEP})_{2} \mathrm{Ph}-$ $\Lambda_{1},\left|-\Delta G^{0}\right|<\lambda$, and the ET process may be assigned to the "normal" region of the Marcus dependence, $\log k_{\mathrm{ET}}=f\left(-\Delta G^{0}\right)$ [66]. It agrees with the conclusion for other Pim-containing systems $[32,61]$. For the Q-substituted dimer $(\mathrm{ZnOEP})_{2} \mathrm{Ph}-$ $\mathrm{A}_{2}$, the ET reaction is probably near the turning point beyond which the system goes into the "inverted" region depending on pyridine action or the solvent polarity rise. The same tendency was discussed for other porphyrin-Q compounds [37].

It should be mentioned that for the Q-substituted dimer $(\mathrm{ZnOEP})_{2} \mathrm{Ph}-\mathrm{A}_{2}$ the ET rate constant in toluene at $293 \mathrm{~K}\left(k_{\mathrm{ET}}=2.86 \times 10^{10} \mathrm{~s}^{-1}\right.$, Table 2$)$ is relatively smaller than those found for monomeric $\mathrm{ZnP}-\mathrm{Q}$ compounds with the same $r_{\mathrm{DA}}$ distances and close $\Delta G^{0}$ values $\left(k_{\mathrm{ET}}=9.5 \times 10^{10} \mathrm{~s}^{-1}\right.$ at $\Delta G^{0}=-0.46 \mathrm{eV}$ and $k_{\mathrm{ET}}=6.0 \times 10^{10} \mathrm{~s}^{-1}$ at $\Delta G^{0}=-0.39 \mathrm{eV}$ in benzene at $293 \mathrm{~K}$ [61]). This may be explained by the competition between the non-radiative $\mathrm{S}-\mathrm{S}$ energy transfer among dimer subunits and charge separation [70]. According to experimental findings and theoretical estimations $[32,68,69]$ in $\mathrm{Zn}$-porphyrin chemical dimers with intercenter distances of $R_{\mathrm{DA}} \approx 11-13 \AA$, rate constants of the non-radiative S-S energy transfer are of $k_{\mathrm{EM}} \approx(3-7) \times 10^{10} \mathrm{~s}^{-1}$. Correspondingly, as far as $k_{\mathrm{EM}} \leqslant k_{\mathrm{ET}}$ for the Q-substituted dimer
$(\mathrm{ZnOEP})_{2} \mathrm{Ph}-\mathrm{A}_{2}$, a slower energy transfer process limits the fast ET leading to the relative decrease of the experimental $k_{\mathrm{ET}}$ values with respect to those found for Q-substituted monomers. In contrast, for the Pim-substituted dimer $(\mathrm{ZnOEP})_{2} \mathrm{Ph}-\mathrm{A}_{1}$ the inverse situation $k_{\mathrm{EM}} \geqslant k_{\mathrm{ET}}$ is realised, and the experimental $k_{\mathrm{ET}}$ values are of the same order of magnitude for dimers and monomers [32].

It seem reasonable to compare our data for $(\mathrm{ZnOEP})_{2} \mathrm{Ph}-\mathrm{A}_{3},(\mathrm{ZnOEP})_{2} \mathrm{Ph}-\mathrm{A}_{4}$ and $(\mathrm{ZnOEP})_{2}$ $\mathrm{Ph}-\mathrm{A}_{5}$ systems and the results obtained for various $A Q-c o n t a i n i n g ~ p o r p h y r i n s ~[62,71,72]$. In the case of $\mathrm{ZnTPP}-\mathrm{AQ}\left(E\left(\mathrm{~S}_{1}\right)=2.0 \mathrm{eV}\right)$ with the same close proximity between the donor and acceptor like in $(\mathrm{ZnOEP})_{2} \mathrm{Ph}-\mathrm{A}_{3}$, the fluorescence is not quenched also in degassed benzene at $293 \mathrm{~K}$ and becomes broader, more red shifted and shorter lived as the solvent polarity is increased [72]. It was proposed that the formation of long-living ( $\sim 2 \mathrm{~ns}$ ) CT-states in ZnTPP-AQ could involve twisting of the AQ moiety with respect to the plane of the porphyrin macrocycle. The addition of a bulky ortho-substituent $\left(\mathrm{CH}_{3}\right.$ group) to $\mathrm{AQ}$ inhibits its rotation about $\mathrm{ZnTPP}-\mathrm{AQ}$ bond due to steric interactions, thus leading to the great diminishing of CT interactions [72]. Based on this idea, we propose that in the case of bulky $\mathrm{C}_{2} \mathrm{H}_{5}$ substituents in $\beta$-positions of pyrrole rings close to AQ (see Fig. 1) the geometric flexibility of the acceptor is inhibited. Thus, in spite of the sufficient $\Delta G^{0}$ value for $(\mathrm{ZnOEP})_{2} \mathrm{Ph}-\mathrm{A}_{3}$ system in toluene (Table 2), ET is not detected yet because of unfavourable mean dihedral angle $\mathrm{ZnOEP^{ \wedge }} \mathrm{AQ}$ leading to a strong decrease of the electronic coupling $V$. Correspondingly, the solvent polarity increase leads to an essential lowering of CT-state energy, and ET takes place even in this case.

In $(\mathrm{ZnOEP})_{2} \mathrm{Ph}-\mathrm{A}_{4}$ system with a longer spacer, steric limitations are absent, but the ET rate constant is small. This result may be attributed to the exponential dependence of ET rate constants on $r_{\mathrm{DA}}$ distance: $k_{\mathrm{ET}}=v \exp \left(-\alpha r_{\mathrm{DA}}\right)[62,66,71]$, where $v$ includes the dependence of ET reaction on the electron exchange matrix element, Franck-Condon factors and $\Delta G^{0}, \alpha$ is a constant depending on the overlap of D and A wave functions. Finally, in $(\mathrm{ZnOEP})_{2} \mathrm{Ph}-\mathrm{A}_{5}$, the ET dynamics are rather complex due to the dynamic equilibrium of various 
conformations caused by the strong flexibility of the spacer in low viscous methylcyclohexane at $293 \mathrm{~K}$.

Thus, on the basis of above results and conclusions two distance-fixed systems, $(\mathrm{ZnOEP})_{2} \mathrm{Ph}-$ $\mathrm{A}_{1}$ and $(\mathrm{ZnOEP})_{2} \mathrm{Ph}-\mathrm{A}_{2}$, with ET clear dynamics have been selected as the corresponding molecular blocks to study ET processes in the triads.

\subsection{Excited states properties of triads without covalently linked acceptors}

Spectral properties typical for all triads under study are shown in Fig. 8. It is seen that for the triad a red shift of the dimer long wavelength absorption $\mathrm{Q}_{x}(0,0)$ band is observed due to extra-ligation effect like pyridine action (compare Fig. 3). Absorption spectra of the triads are a linear combination of the corresponding dipyridinated dimer $(\mathrm{ZnOEP})_{2} \mathrm{Ph}$ and the extra-ligand, with only small differences in wavelength maxima and band shapes. Thus, the interaction between the two subunits is weak in the ground state, and they retain their individual identities.

Fluorescence spectra of the triads of various geometry (I and II) and extra-ligand nature (IIA, IIB and IIC) (Fig. 2), do show strong quenching of
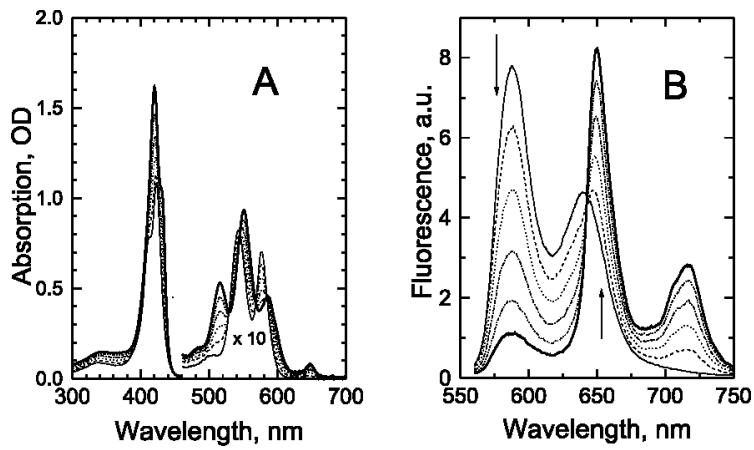

Fig. 8. Absorption (A) and fluorescence (B, $\lambda_{\mathrm{ex}}=546 \mathrm{~nm}$, isosbestic point) spectra of $(\mathrm{ZnOEP})_{2} \mathrm{Ph}$ with increasing amounts of extra-ligand $\mathrm{H}_{2} \mathrm{P}\left(m^{\wedge} \mathrm{Pyr}\right)_{2}$-(iso- $\left.\mathrm{PrPh}\right)_{2}$ (toluene, 293 $\mathrm{K})$. Concentration of $(\mathrm{ZnOEP})_{2} \mathrm{Ph}$ at the beginning of titration is $C_{\mathrm{D} 0}=1.9 \times 10^{-6} \mathrm{M}$. The dimer:ligand molar ratio varies from $x=1: 0$ to $1: 1(0.0,0.2,0.4,0.6,0.8,1.0)$. Bold curves correspond to the triad spectra. The unshifted low-intensity fluorescence band at $\lambda_{\max }=586 \mathrm{~nm}$ in triad solution at $x=1: 1$ belongs to the remaining uncomplexed dimer. the dimer fluorescence. In all cases the fluorescence spectra of the triads mainly consist of the extraligand fluorescence bands (Fig. 8). In toluene at $293 \mathrm{~K}$, fluorescence excitation spectra of the triads detected at extra-ligands fluorescence bands $\left(\lambda_{\text {det }} \geqslant 720 \mathrm{~nm}\right.$, Fig. 9B, curve 1$)$ clearly show the existence of absorption bands of the dimer (549 $\mathrm{nm}$ and $587 \mathrm{~nm}$, Fig. 8). Therefore it seems reasonable to explain these facts by the S-S energy transfer (S-S EET) Zn-dimer ${ }^{*} \rightarrow$ extra-ligand.
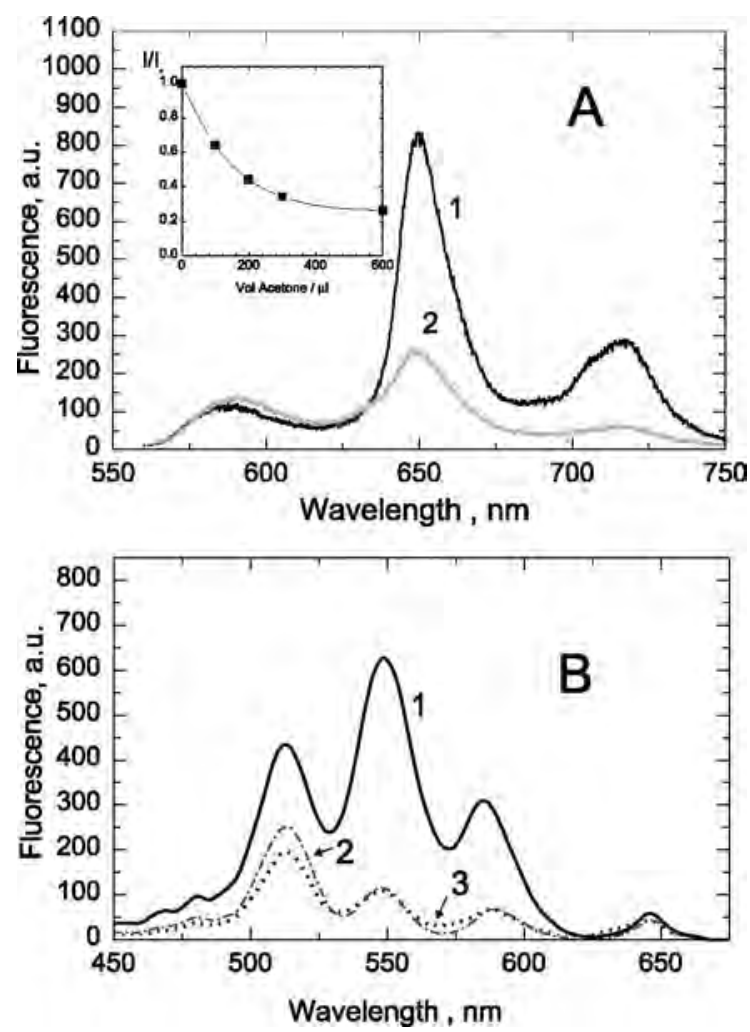

Fig. 9. Fluorescence (A, $\left.\lambda_{\mathrm{ex}}=546 \mathrm{~nm}\right)$ and fluorescence excitation spectra $\left(\mathrm{B}, \lambda_{\mathrm{em}}=720 \mathrm{~nm}\right)$ of the triad $(\mathrm{ZnOEP})_{2} \mathrm{Ph} \otimes \mathrm{H}_{2} \mathrm{P}$ $\left(m^{\wedge} \mathrm{Pyr}\right)_{2}$-(iso- $\left.\mathrm{PrPh}\right)_{2}\left(x=0.92, C_{\mathrm{D} 0}=2.6 \times 10^{-6}\right)$ in toluene (1) and toluene $+17 \mathrm{vol} \%$ of acetone solutions at $293 \mathrm{~K}(2)$. Curve $3 \mathrm{~B}$ corresponds to fluorescence excitation spectrum $\left(\lambda_{\mathrm{em}}=720\right.$ $\mathrm{nm})$ of individual extra-ligand $\mathrm{H}_{2} \mathrm{P}\left(m^{\wedge} \mathrm{Pyr}\right)_{2}$-(iso- $\left.\mathrm{PrPh}\right)_{2}$ in toluene. Insert: dependence of the extra-ligand fluorescence intensity in the triad $\left(\lambda_{\mathrm{ex}}=650 \mathrm{~nm}\right.$, integrated region of $720-750$ $\mathrm{nm}$ ) on acetone admixture to toluene solution with $V_{0}=2.9 \mathrm{ml}$ (the dilution effect has been taken into account). The intensity of the dimer fluorescence band at $586 \mathrm{~nm}\left(\lambda_{\mathrm{ex}}=546 \mathrm{~nm}\right)$ increases only slightly indicating that the triads are not destroyed upon acetone addition up to $17 \mathrm{vol} \%$. 
Nevertheless, the real dynamics of electronic energy deactivation in the triads is not governed by $\mathrm{S}-\mathrm{S}$ EET processes only. For instance, in nonpolar toluene at $293 \mathrm{~K}$ for the triad $(\mathrm{ZnOEP})_{2}$ $\mathrm{Ph} \otimes \mathrm{H}_{2} \mathrm{P}(m \hat{\mathbf{P}} \text { yr })_{2}$-(iso- $\left.\mathrm{PrPh}\right)_{2}$ excited at $650 \mathrm{~nm}$ (where only the extra-ligand absorbs), the extraligand fluorescence quantum efficiency is reduced as compared to the individual $\mathrm{H}_{2} \mathrm{P}\left(m^{\wedge} \mathrm{Pyr}\right)_{2}$-(iso$\mathrm{PrPh})_{2}$ [44]. Fig. 9A shows also that the increase of the solvent polarity by a subsequent acetone addition to toluene leads to the decrease of the extraligand fluorescence intensity (bands at $650 \mathrm{~nm}$ and $714 \mathrm{~nm}$ ). In contrast, the fluorescence of the individual extra-ligand does not show fluorescence quenching upon acetone addition. Interestingly, that at $17 \mathrm{vol} \%$ of acetone admixture in toluene the form of the excitation spectrum of the triad becomes almost identical to that of the individual extra-ligand $\mathrm{H}_{2} \mathrm{P}\left(m^{\wedge} \mathrm{Pyr}\right)_{2}$-(iso- $\left.\mathrm{Pr} \mathrm{Ph}\right)_{2}$ (Fig. 9B). This indicates that the sensitisation effect due to $\mathrm{S}-$ $S$ EET is absent in the last case, though the usual through-space singlet-singlet energy transfer in multiporphyrin arrays is hardly dependent on the solvent polarity [73]. At the same time, data of Fig. $9 \mathrm{~A}$ evidently show that the dimer emission in the triad remains strongly quenched upon the solvent polarity increase.
To investigate the excited-state dynamics, the fluorescence decay times of the triads and individual subunits were evaluated using TCSPC measurements (Fig. 10) and a global analysis fit with three time constants (Table 3). The main conclusion is that the fluorescence decays of extraligands in the triads are reduced noticeably with respect to those for individual uncomplexed porphyrin and chlorin free bases in pure toluene. The decay time shortening increases upon the solvent polarity rise $\left(\tau_{\mathrm{S}}=5.5 \mathrm{~ns}\right.$ for $\mathrm{H}_{2} \mathrm{P}\left(m^{\wedge} \mathrm{Pyr}\right)_{2}$-(iso$\mathrm{PrPh})_{2}$ in the triad in toluene $+7 \mathrm{vol} \%$ of acetone), the last tendency correlates with a pronounced decrease of the extra-ligand fluorescence quantum yield (Fig. 9A). Additionally, according to our recent results [44], the fluorescence intensity of the extra-ligand in the triad $(\mathrm{ZnOEP})_{2} \mathrm{Ph} \otimes \mathrm{H}_{2} \mathrm{P}$ $\left(m^{\wedge} \mathrm{Pyr}\right)_{2}$-(iso- $\left.\mathrm{PrPh}\right)_{2}$ is decreased upon the temperature lowering $(278-160 \mathrm{~K})$. These observations cannot be attributed to S-S EET processes, rather the possibilities of photoinduced charge separation or other radiationless processes have to be taken into account.

Femtosecond pump-probe data obtained for the triad $(\mathrm{ZnOEP})_{2} \mathrm{Ph} \otimes \mathrm{H}_{2} \mathrm{P}\left(m^{\wedge} \mathrm{Pyr}\right)_{2}$-(iso- $\left.\mathrm{PrPh}\right)_{2}$ in toluene at $293 \mathrm{~K}$ have been discussed in details in our previous paper [44] where the formation of

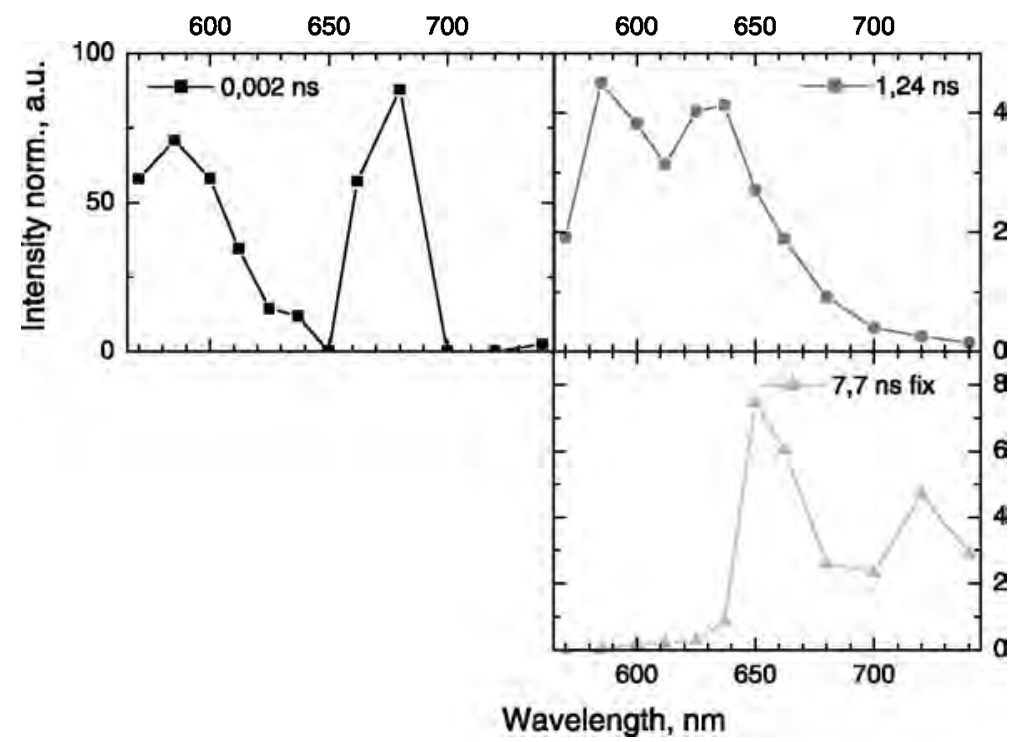

Fig. 10. Decay-associated spectra of the triad $(\mathrm{ZnOEP})_{2} \mathrm{Ph} \otimes \mathrm{H}_{2} \mathrm{P}\left(m^{\wedge} \mathrm{Pyr}\right)_{2}$-(iso-PrPh$)_{2}$ (toluene, $293 \mathrm{~K}$, $\lambda_{\mathrm{ex}}=546 \mathrm{~nm}$, detection range of $570-750 \mathrm{~nm}$ ) derived from global analysis of 12 TCSPC time-resolved fluorescence measurements. The global $\chi^{2}$ value was 1.15 . 
Table 3

Structural and photophysical parameters for self-assembled triads based on the dimer $(\mathrm{ZnOEP})_{2} \mathrm{Ph}$ and various extra-ligands (toluene, $293 \mathrm{~K}$ )

\begin{tabular}{llllllllll}
\hline Ligand $^{\mathrm{a}}$ & $r_{\mathrm{DA}}^{\mathrm{b}}(\AA)$ & $\begin{array}{l}E_{\mathrm{A}}^{\mathrm{redc}} \\
(\mathrm{eV})\end{array}$ & $\begin{array}{l}E\left(\mathrm{~S}_{1}^{\mathrm{D}}\right)^{\mathrm{d}} \\
(\mathrm{eV})\end{array}$ & $\begin{array}{l}\Delta G_{\mathrm{S}}{ }^{\mathrm{e}} \\
(\mathrm{eV})\end{array}$ & $\begin{array}{l}E(\mathrm{IP})^{\mathrm{f}} \\
(\mathrm{eV})\end{array}$ & $\begin{array}{l}\tau_{\mathrm{S} 0}^{\mathrm{Dimg}} \\
(\mathrm{ns})\end{array}$ & $\tau_{\mathrm{S} 0}^{\mathrm{L}}{ }^{\mathrm{h}}(\mathrm{ns})$ & $\tau_{1}{ }^{\mathrm{i}}(\mathrm{ns})$ & $\tau_{2}{ }^{\mathrm{j}}(\mathrm{ns})$ \\
\hline $\mathrm{H}_{2} \mathrm{P}\left(m^{\wedge} \mathrm{Pyr}\right)_{2}-(\text { iso-PrPh})_{2}$ & 8.8 & -0.98 & 1.91 & 0.287 & 1.90 & 1.15 & 9.5 & 7.7 & 1.24 \\
$\mathrm{H}_{2} \mathrm{P}(m-\mathrm{Pyr})_{2}-(\text { iso-PrPh})_{2}$ & 8.2 & -0.98 & 1.91 & 0.287 & 1.90 & 1.15 & 9.3 & 6.2 & 1.23 \\
$\mathrm{H}_{2} \mathrm{Chl}(m-\mathrm{Pyr})_{2}$ & 8.2 & -1.05 & 1.89 & 0.287 & 1.97 & 1.15 & 8.3 & 6.6 & 1.24 \\
$\mathrm{H}_{2} \mathrm{THP}(m-\mathrm{Pyr})_{2}$ & 8.2 & -1.03 & 1.66 & 0.287 & 1.95 & 1.15 & 4.3 & 4.3 & 1.23 \\
\hline
\end{tabular}

${ }^{\mathrm{a}}$ The structures of the triads are shown in Fig. 2.

${ }^{\mathrm{b}}$ Intercenter distances $r_{\mathrm{DA}}$ were estimated from optimised structures of the triads (HyperChem software package, release 4, semiempirical method PM3).

${ }^{\mathrm{c}}$ The oxidation potential for coordinated dimer $(\mathrm{ZnOEP})_{2} \mathrm{Ph}$ was taken to be $E_{1 / 2}^{\mathrm{ox}}=0.63 \mathrm{~V}$ (like for pyridinated $\mathrm{ZnOEP}$ in $\mathrm{DMF}$ vs SCE [59,60]). Reduction potentials for extra-ligands have been extracted from literature data (in DMF vs SCE) [78,79] taking into account that pyridyl substituents increase the reduction potential of free base porphyrins and chlorins [80].

${ }^{d}$ The energy levels of the extra-ligand locally excited $S_{1}$-states were determined on the basis of the corresponding fluorescence and absorption $\mathrm{Q}(0,0)$ bands.

${ }^{\mathrm{e}}$ The estimations of $\Delta G_{\mathrm{S}}$ terms for the triads were done using the expression shown in the description for Table 2, donor and acceptor radii are of $r_{\mathrm{D}}=r_{\mathrm{A}}=5.5 \AA$.

${ }^{f}$ The energy levels of the ion pair states in toluene were estimated by $E(\mathrm{IP})=e\left(E_{\mathrm{D}}^{\mathrm{ox}}-E_{\mathrm{A}}^{\mathrm{red}}\right)+\Delta G_{\mathrm{S}}[63,64]$.

${ }^{g}$ Measured for the individual dimer in toluene+pyridine.

${ }^{\mathrm{h}}$ Measured for the corresponding individual extra-ligand in toluene.

${ }^{i}$ Attributed to the complexed extra-ligand according to TCSPC data analysis.

${ }^{j}$ Attributed to the uncomplexed dimer according to TCSPC data analysis.

CT states has been appropriately detected. It follows from those results that the non-radiative relaxation of the dimer $\mathrm{S}_{1}$-state in the triads realises within $\sim 1.7$ ps.

Thus, static and time-resolved data indicate that the non-radiative deactivation of the dimer locally excited $S_{1}$-state in the triads is caused by both S-S-EET and ET processes (Fig. 11, rate constants $k_{5}$ and $k_{6}$ ). The competition between SS-EET and ET channels depends on photophysical and redox parameters of the subunits and may be driven by properties of surrounding. Applying

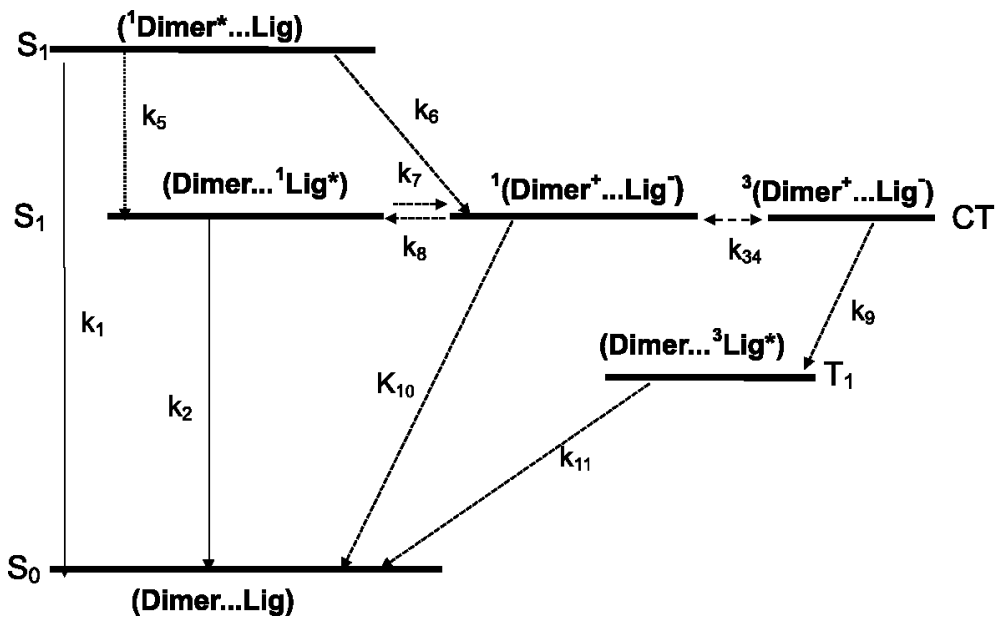

Fig. 11. Schematic energy level diagram for low-lying locally excited singlet states of the dimer $\left(\mathrm{ZnOEP}_{2} \mathrm{Ph}\left\{\mathrm{S}_{1},\left(\mathrm{Dimer}{ }^{*} \ldots \mathrm{H}_{2} \mathrm{P}\right)\right\}\right.$, the extra-ligand $\mathrm{H}_{2} \mathrm{P}\left\{\mathrm{S}_{1}\right.$, (Dimer $\left.\left.\cdots{ }^{1} \mathrm{H}_{2} \mathrm{P}^{*}\right)\right\}$, locally excited triplet state of $\mathrm{H}_{2} \mathrm{P}\left\{\mathbf{T}_{1}\left(\right.\right.$ Dimer $\left.\left.\cdots{ }^{3} \mathrm{H}_{2} \mathrm{P}^{*}\right)\right\}$, radical ion pair singlet $\left\{\mathrm{CT},{ }^{1}\left(\right.\right.$ Dimer $\left.\left.^{+} \cdots \mathrm{H}_{2} \mathrm{P}^{-}\right)\right\}$and triplet $\left\{\mathrm{CT},{ }^{3}\left(\right.\right.$ Dimer $\left.\left.^{+} \ldots \mathrm{H}_{2} \mathrm{P}^{-}\right)\right\}$states. 
Foerster inductive-resonant model [74] to the triads with known geometrical, spectral and kinetic parameters (dipole-dipole distances $R_{\mathrm{DA}}=8.2$ $13.7 \AA$, orientation factors $k^{2}=0.47 / 0.75$, fluorescence lifetime $\tau_{\mathrm{S}}^{0}=1.15 \mathrm{~ns}$, quantum yield $\varphi_{\mathrm{S}}=0.012$ for dipyridinated $(\mathrm{ZnOEP})_{2} \mathrm{Ph}$, toluene, $293 \mathrm{~K}$ ) we calculated spectral overlap integrals $J=\int_{0}^{\infty} f_{\mathrm{D}}(v) \varepsilon_{\mathrm{A}}(v) \frac{\mathrm{d} v}{v^{4}}=1.2 \times 10^{-14}-5.9 \times$ $10^{-14} \mathrm{~cm}^{-6} \mathrm{M}^{-1}$ and critical transfer distances $R_{0}^{\text {theor }}=16.8-17.2 \AA$. Correspondingly, theoretical values of S-S EET rate constants are estimated to be $k_{5}=k_{\mathrm{EET}}=\left(1 / \tau_{\mathrm{S}}\right)\left(R_{0}^{\text {theor }} / r_{\mathrm{DA}}\right)^{6} \approx 6.7 \times 10^{10}$ $-7.5 \times 10^{10} s f^{-1}$, and the dimer $S_{1}$-state decay has to be decreased to values of $\sim 15-13$ ps due to $\mathrm{S}-\mathrm{S}$ EET only. For the triads based on (ZnTPP) $)_{2}$ in cyclohexane, it was expected that the excitation energy transport $\mathrm{Zn}$-dimer ${ }^{*} \rightarrow$ extra-ligand is on the time scale of $\leqslant 10$ ps [49]. The experimental value of $k_{\mathrm{EET}}=2.9 \times 10^{11} \mathrm{~s}^{-1}\left(\tau_{\mathrm{S}}=3.5 \mathrm{ps}\right)$ was obtained for $\mathrm{ZnP}-\mathrm{H}_{2} \mathrm{PF}$ dimer with the distances $r_{\mathrm{DA}}$ of the same order [75]. In the later case, the enhanced (with respect to Foerster model calculations) excited-state energy-transfer rates have been attributed to enhanced electronic coupling between the porphyrin constituents across the $p$ phenylene linker (through-bond mechanism) with a possible influence of a ground-state hole/electron hopping. In this respect, the observed strong shortening of the dimer $(\mathrm{ZnOEP})_{2} \mathrm{Ph} \mathrm{S}_{1}$-state decays in the triads (toluene, $293 \mathrm{~K}$ ) is most likely attributed to a Foerster-type EET and an additional ET process. This quenching is followed by the population of the locally excited $S_{1}$-state of the extra-ligand via S-S EET with a rate constant $k_{5}$ and the formation of the radical ion pair singlet state via $\mathrm{ET}$ process with a rate constant $k_{6}$ (Fig. 11).

Data of Table 3 shows that for the triads of different geometry containing $\left(\mathrm{H}_{2} \mathrm{P}\left(m^{\wedge} \mathrm{Pyr}\right)_{2}\right.$-(iso$\mathrm{PrPh})_{2}$ and $\mathrm{H}_{2} \mathrm{P}(m \text {-Pyr })_{2}$-(iso- $\left.\mathrm{PrPh}\right)_{2}$ (structures I and IIA in Fig. 2), the extra-ligand $\tau_{\mathrm{S}}$ shortening is of the same order of magnitude. This fact may be explained by a close proximity of extra-ligand macrocycles to $\pi$-conjugated electronic system of the dimer resulting in a high electronic coupling for both triads which is hardly dependent on $r_{\mathrm{DA}}$ deviations. Interestingly, in the triads of the same geometry but containing $(\mathrm{ZnTPP})_{2}$ dimer,
ET process (Zn-dimer ${ }^{*} \ldots$ extra-ligand $) \rightarrow(\mathrm{Zn}-$ dimer $^{+}$...extra-ligand $\left.{ }^{-}\right)$was not detected in nonpolar cyclohexane at $293 \mathrm{~K}$ [49]. The reason of that is explained by the higher value of the oxidation potential for pyridinated ZnTPP $\left(E_{1 / 2}^{\mathrm{ox}}=0.77 \mathrm{~V}\right.$ in DMF vs SCE [60]) with respect to that for $\mathrm{ZnOEP}\left(E_{1 / 2}^{\mathrm{ox}}=0.63 \mathrm{~V}\right.$ in DMF vs SCE [59]), thus leading to the situation unfavorable for $\mathrm{ET}$, namely $E(\mathrm{IP})>E\left(\mathrm{~S}_{1}\right)$.

It is seen from Fig. 11 that the deactivation of the extra-ligand $S_{1}$-state in the triads is governed by the competition of various processes in nonpolar toluene at $293 \mathrm{~K}$. The photoinduced hole transfer from the extra-ligand $\mathrm{S}_{1}$-state to the dimer with a rate constant $k_{7}$ leads to the singlet CT-state formation. On the other hand, the fast repopulation of the extra-ligand $S_{1}$-state is caused by the effective thermally activated charge recombination process $\left(\right.$ Dimer $\left.^{+} \ldots \mathrm{Lig}^{-}\right) \stackrel{k_{8}}{\rightarrow}\left(\right.$ Dimer $\left.\ldots{ }^{1} \mathrm{Lig}^{*}\right)$. The complex $\mathrm{S}_{1}$-state dynamics results in a noticeable $\tau_{\mathrm{S}}$ shortening and fluorescence quantum yield $\varphi_{F}$ decrease for extra-ligands in the triads with respect to those for individual porphyrin free bases. In fact, the presented scheme explains the existence of sensitised and/or activated fluorescence of the extra-ligand in pure toluene at $293 \mathrm{~K}$ (Fig. 9, curve $1 \mathrm{~B})$ as a result of simultaneous realisation of $\mathrm{S}_{-} \mathrm{S}$ EET, ET and repopulation processes. The increase of the solvent polarity leads to CT-state lowering and manifests itself in an additional quenching of the extra-ligand fluorescence as well as in the absence of the sensitising effect via the dimer, which may hint to ET processes involved in the later case. At last, we have shown recently for the triads [44], that the direct intersystem crossing $S_{1} \geq T_{1}$ in the extra-ligand subunit is probably low in comparison with the processes discussed above. The population of the extra-ligand locally excited $\mathrm{T}_{1}$-state may take place from the upper lying triplet radical ion pair state ${ }^{3}\left(\right.$ Dimer $\left.^{+} \ldots \mathrm{Lig}^{-}\right)$formed via the spin rephasing between the singlet and triplet radical ion pairs (rate constant $k_{34}$, Fig. 11).

The analysis of data collected for the triad IIB with $\mathrm{H}_{2} \mathrm{Chl}(m \text {-Pyr })_{2}$ indicates that the non-radiative deactivation of the extra-ligand $\mathrm{S}_{1}$-state may take place via the thermal activation of the closelying upper CT states. In addition, according to Ref. [76] the $\tau_{\mathrm{S}}$ shortening may be enhanced in this 
case by mixing of a close-lying CT state with the extra-ligand $\mathrm{S}_{1}$-state thus leading to the non-radiative transition $\mathrm{S}_{1} \gtrsim \mathrm{S}_{0}$ strengthening in $\mathrm{H}_{2} \mathrm{Chl}(\mathrm{m}$ $\mathrm{Pyr})_{2}$ subunit. The last effect is the reason of a strong decay shortening of the extra-ligand triplet state observed by us recently in porphyrin triad containing di-pentafluorinated extra-ligand (electron acceptor) [44]. At last, for the triad IIC with $\mathrm{H}_{2} \mathrm{THP}(m-\mathrm{Pyr})_{2}$ the energy of the locally excited $\mathrm{S}_{1}$-state is smaller by $0.29 \mathrm{eV}$ with respect to the energy of the CT-state. Thus, both quenching mechanisms being discussed are switched off practically, and $\mathrm{H}_{2} \mathrm{THP}(m-\mathrm{Pyr})_{2}$ fluorescence quenching is not detected in this case.

Experimental data shows also that the fluorescence quenching of the dimer $\left(\tau_{\mathrm{S}}^{0}=1.15 \mathrm{~ns}\right.$, $\tau_{\mathrm{S}}=1.7 \mathrm{ps}$ ) is essentially stronger with respect to that observed for the extra-ligands (Table 3). It means that $k_{6}$ value has to be higher essentially compared to $k_{7}$. On the basis of Marcus theory (Eqs. (1) and (2)) this difference is explained at least by two reasons (at the same reorganisation energy $\lambda$ ): (i) the Gibbs free energy for ET from the dimer to the extra-ligand via D-A LUMO's is estimated to be $\Delta G^{0}=-0.23 \mathrm{eV}$, while $\Delta G^{0}=-0.01$ $\mathrm{eV}$ for the photoinduced hole transfer from the extra-ligand to the dimer via D-A HOMO's; (ii) being weakened by the screening field of the electron from the LUMO of the acceptor, the electronic coupling term $V$ for the photoinduced hole transfer is smaller essentially than that for the direct ET transfer. Additionally, the observed quenching of the extra-ligand fluorescence caused by a hole transfer from the extra-ligand to the $\mathrm{Zn}$ porphyrin dimer is weakened by thermal exchange of the close lying CT-state and the extra-ligand locally excited $\mathrm{S}_{1}$-state in toluene at $293 \mathrm{~K}$. The theoretical description of the competition between energy and CT events in the triads will be presented in our forthcoming paper [77].

\subsection{Dynamics of relaxation processes in triads with covalently linked electron acceptors}

The absorption spectra of the triads with additional electron acceptors (Fig. 12A) do not differ practically from those obtained for triads without $\mathrm{Q}$ or Pim (Fig. 8A). It means that in A-containing
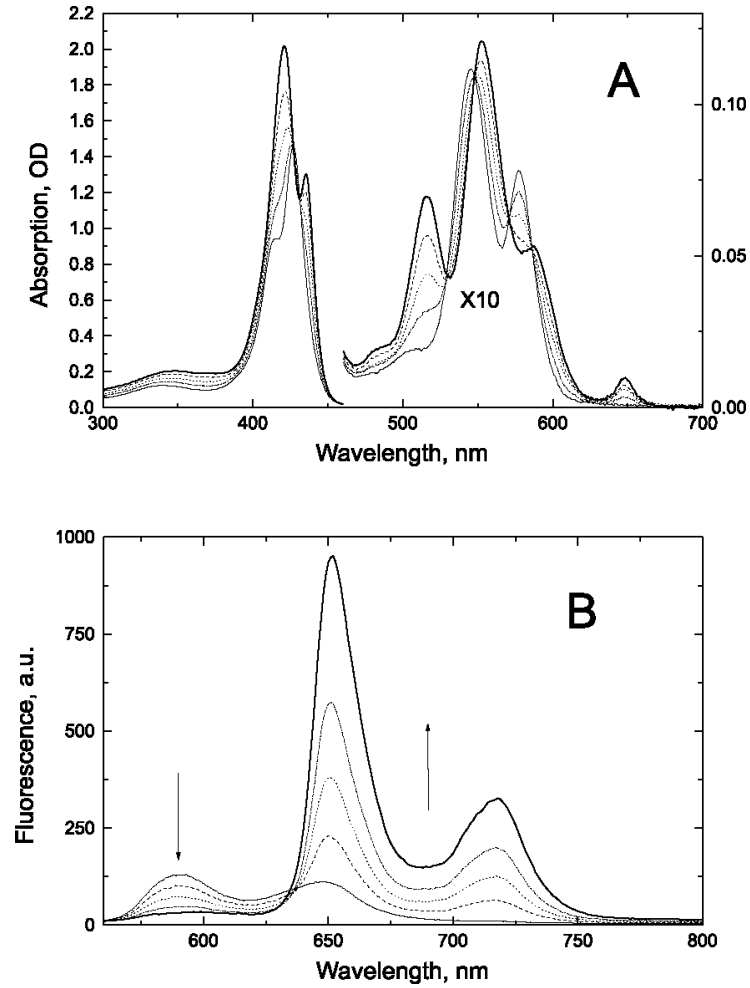

Fig. 12. Absorption (A) and fluorescence (B, $\lambda_{\mathrm{ex}}=546 \mathrm{~nm}$, isosbestic point) spectra of $(\mathrm{ZnOEP})_{2} \mathrm{Ph}-\mathrm{A}_{2}$ with increasing amounts of extra-ligand $\mathrm{H}_{2} \mathrm{P}\left(m^{\wedge} \mathbf{P y r}\right)_{2}$-(iso-PrPh) (toluene, 293 $\mathrm{K})$. Concentration of $(\mathrm{ZnOEP})_{2} \mathrm{Ph}-\mathrm{A}_{2}$ at the beginning of titration is $C_{\mathrm{D} 0}=3.03 \times 10^{-6} \mathrm{M}$. The dimer:ligand molar ratio varies from $x=1: 0$ to $1: 1(0.0,0.25,0.50,0.75,1.0)$. Bold curves correspond to the triad spectra. The unshifted low-intensity fuorescence band at $\lambda_{\max }=586 \mathrm{~nm}$ in triad solution at $x=1: 1$ belongs to the remaining uncomplexed dimer.

triads porphyrin chromophores act as entirely independent light absorbing entities.

Titration experiments indicate also that fluorescence spectra of A-containing triads are characterised by the substantial quenching of the zincporphyrin dimer fluorescence bands (Fig. 12B). This important observation implies that the initial fluorescence of the systems $(\mathrm{ZnOEP})_{2} \mathrm{Ph}-\mathrm{A}_{1}$ and $(\mathrm{ZnOEP})_{2} \mathrm{Ph}-\mathrm{A}_{2}$ being strongly quenched due to ET process from the dimer to A (see Section 3.1), does show a remarkable additional quenching upon the triad formation in toluene at $293 \mathrm{~K}$. The second found feature of the triads with covalently linked acceptors is that fluorescence quantum 
efficiencies $\left(\varphi_{\mathrm{F}}\right)$ of complexed extra-ligands are essentially smaller as compared to those for the same extra-ligands in the corresponding triads without A's in toluene at $293 \mathrm{~K}$. The decrease of $\varphi_{\mathrm{F}}$ values is more pronounced for the Q-containing triad IV with respect to that for the Pim-containing triad V.

In order to analyse the possible reasons of this additional quenching channels, fluorescence excitation spectra of the triads $\mathrm{V},(\mathrm{ZnOEP})_{2} \mathrm{Ph}-$ $\mathrm{Pim} \otimes \mathrm{H}_{2} \mathrm{P}\left(m^{\wedge} \mathrm{Pyr}\right)_{2}$-(iso-PrPh $)_{2}$ and IV, $(\mathrm{ZnOEP})_{2}$ $\mathrm{Ph}-\mathrm{Q} \otimes \mathrm{H}_{2} \mathrm{P}\left(m^{\wedge} \mathrm{Pyr}\right)_{2}$-(iso- $\left.\mathrm{PrPh}\right)_{2}$ were measured at the free-base fluorescence band at $720 \mathrm{~nm}$ upon the solvent polarity increase (Fig. 13). The comparison of the corresponding spectra obtained for these two triads and for the triad without A (Fig. 9B) reveals the following principal differences. In the case of the triad V with Pim in toluene at $293 \mathrm{~K}$ (Fig. 13A, curve 1), the excitation spectrum shows the existence of absorption bands of the zincporphyrin dimer ( 549 and $587 \mathrm{~nm}$ ) as well as those of free-base porphyrin $(516,552,592$ and $647 \mathrm{~nm})$. Nevertheless, the relative intensities of the zincporphyrin dimer bands are smaller with respect to those found in the triads absorption spectra (Figs. $8 \mathrm{~A}$ and $12 \mathrm{~A}$ ). Additionally, the relative intensities of the dimer bands (compared with those for the extra-ligand) in the excitation spectrum of Pimcontaining triad $\mathrm{V}$ are smaller than intensities of the corresponding bands measured for the same triad without A (compare curve 1 in Fig. 13A and curve 1 in Fig. 9B). Fig. 13A shows also that the increase of the solvent polarity manifests itself in the significant change of the excitation spectrum of the triad $\mathrm{V}$ that becomes almost identical to that of the individual extra-ligand $\mathrm{H}_{2} \mathrm{P}\left(m^{\wedge} \mathrm{Pyr}\right)_{2}$-(iso$\mathrm{PrPh})_{2}$. These spectral transformations for the triad $\mathrm{V}$ are accompanied by the fluorescence quenching of the complexed extra-ligand (by 1.5-2 times at $9 \mathrm{vol} \%$ of acetone). At the same time, the dimer emission in the triad $\mathrm{V}$ remains strongly quenched upon the solvent polarity increase. The decrease of sensitisation effect in the Pim-containing triad $\mathrm{V}$ with respect to that for the same triad without A may be connected with the relative weakening of the energy transfer $\mathrm{Zn}$-dimer ${ }^{*} \rightarrow$ extra-ligand for $(\mathrm{ZnOEP})_{2} \mathrm{Ph}-\mathrm{Pim} \otimes \mathrm{H}_{2} \mathrm{P}\left(m^{\wedge} \mathrm{Pyr}\right)_{2^{-}}$ (iso- $\mathrm{PrPh})_{2}$ in toluene at $293 \mathrm{~K}$. In polar solvents
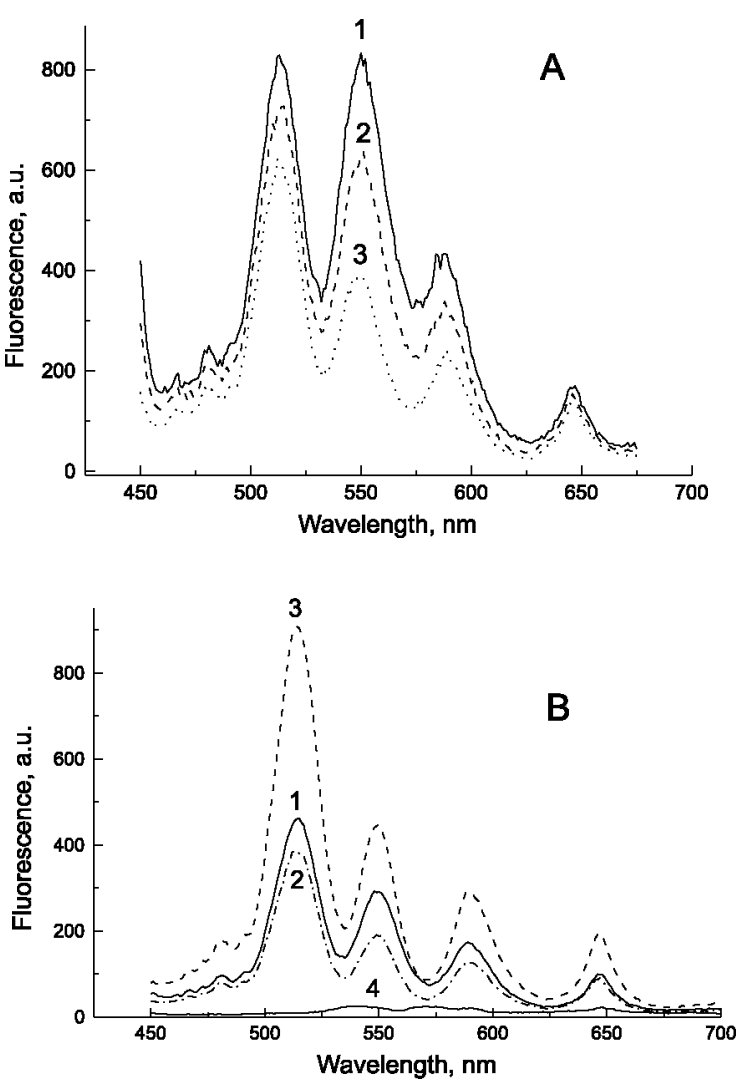

Fig. 13. Fluorescence excitation spectra $\left(\lambda_{\mathrm{em}}=720 \mathrm{~nm}\right)$ of the triads $\mathrm{V},(\mathrm{ZnOEP})_{2} \mathrm{Ph}-\mathrm{Pim} \otimes \mathrm{H}_{2} \mathrm{P}\left(m^{\wedge} \mathrm{Pyr}\right)_{2}$-(iso-PrPh $)_{2}$ (A) and $\mathrm{IV},(\mathrm{ZnOEP})_{2} \mathrm{Ph}-\mathrm{Q} \otimes \mathrm{H}_{2} \mathbf{P}\left(m^{\wedge} \mathbf{P y r}\right)_{2}$-(iso- $\left.\mathrm{PrPh}\right)_{2}$ (B), upon increase of the solvent polarity at $293 \mathrm{~K}$ (a subsequent acetone addition to toluene up to $17 \mathrm{vol} \%$ or acetonitrile up to $9 \mathrm{vol} \%$ do not lead to the triad destroying). A: pure toluene (1), +3 vol $\%$ (2), and +9 vol $\%$ (3) of acetone. B: pure toluene (1) and $+9 \mathrm{vol} \%$ of acetonitrile (2); fluorescence excitation spectra of individual extra-ligand (3) and the dimer $(\mathrm{ZnOEP})_{2} \mathrm{Ph}-\mathrm{Q}(4$, multiplited by 10 ) in toluene at $\lambda_{\mathrm{em}}=720 \mathrm{~nm}$.

experimental results do not show the manifestation of S-S EET in the triad V.

For the triad IV containing a stronger electron acceptor $Q$, the fluorescence excitation spectrum $\left(\lambda_{\mathrm{det}}=720 \mathrm{~nm}\right)$ measured in pure toluene at $293 \mathrm{~K}$ even, are almost identical in shape to that of the individual extra-ligand $\mathrm{H}_{2} \mathrm{P}\left(m^{\wedge} \mathrm{Pyr}\right)_{2}$-(iso- $\left.\mathrm{PrPh}\right)_{2}$ (Fig. 13B). Fig. 13B shows also that this spectrum does not change in shape practically upon the solvent polarity rise. In the Q-containing triad IV, like in previous case, the rise of the solvent polarity leads to the fluorescence quenching of the 
complexed extra-ligand (by $1.3-1.4$ times at $9 \mathrm{vol} \%$ of acetonitrile), while the dimer emission in this triad remains strongly quenched. The observed experimental features for the Q-containing triad may be considered as evidence that S-S EET process Zn-dimer ${ }^{*} \rightarrow$ extra-ligand is slow compared to other pathways (including ET) of electronic energy deactivation of $\mathrm{S}_{1}$-excited dimer. Interestingly, for the self-assembled Q-containing triads of the same geometry but based on the $(\mathrm{ZnTPP})_{2}$ dimer, fluorescence excitation spectra clear show the efficient (within $\leqslant 10 \mathrm{ps)} \mathrm{S-S} \mathrm{energy}$ transfer $(\mathrm{ZnTPP})_{2}^{*} \rightarrow$ extra-ligand in non-polar cyclohexane at $293 \mathrm{~K}$ [49]. As was discussed above (Section 3.2), because of different $E_{1 / 2}^{\text {ox }}$ values for $(\mathrm{ZnTPP})_{2}$ and $(\mathrm{ZnOEP})_{2} \mathrm{Ph}$ the CT-state energy of the radical ion pair $\left[(\mathrm{ZnTPP})_{2}^{+} \ldots\right.$ extra-ligand $\left.{ }^{-}\right]$ $E(\mathrm{IP})=2.07 \mathrm{eV}$ is higher than the energy $E\left(\mathrm{~S}_{1}\right)=1.99 \mathrm{eV}$ of the dimer $(\mathrm{ZnTPP})_{2} \mathrm{~S}_{1}$-state (toluene, $293 \mathrm{~K}$ ). Thus, in the later case the photoinduced ET process is low probable because of energetic reasons, and S-S EET is dominant pathway for the dimer $S_{1}$-state non-radiative relaxation.

Direct time-resolved fluorescence measurements support a strong shortening of the extra-ligand $\mathrm{S}_{1}$ state. Decay-associated spectra are shown in Fig. 14 and Table 4 lists the evaluated fluorescence decay times for the complexed extra-ligands in all $A$-containing triads. The comparative analysis of the data collected in Table 4 indicates the essential shortening of fluorescence decays for all extra-ligands in A-containing triads $\left(\tau_{\mathrm{S}}^{\mathrm{D}}\right)$ with respect to those found for the same triads without $A\left(\tau_{S_{0}}^{\mathrm{D}}\right)$. In addition, some experimental facts should be mentioned. The strongest decrease of $\tau_{\mathrm{S}}^{\mathrm{D}}$ values is observed for $\mathrm{H}_{2} \mathrm{P}(m-\mathrm{Pyr})_{2}$-(iso- $\left.\mathrm{PrPh}\right)_{2}$ and $\mathrm{H}_{2} \mathrm{P}$ $\left(m^{\wedge} \mathrm{Pyr}\right)_{2}$-(iso- $\left.\mathrm{PrPh}\right)_{2}$ among all extra-ligands being used. For these two ligands the quenching effect is hardly dependent on the Q-containing triad geometry (triads IIIA and IV, Fig. 2). For the triads of the same geometry but having extra-ligands of various nature (triads IIIA, IIIB and IIIC, Fig. 2), the extra-ligand fluorescence quenching decreases in the following sequence: $\mathrm{H}_{2} \mathrm{P}(m \text {-Pyr })_{2}$-(iso$\mathrm{PrPh})_{2} \rightarrow \mathrm{H}_{2} \mathrm{Chl}(m \text {-Pyr })_{2} \rightarrow \mathrm{H}_{2} \mathrm{THP}(m-\mathrm{Pyr})_{2}$. In the Q- and Pim-containing triads of the same geometry with the same extra-ligands (triads IV and $\mathrm{V})$, the fluorescence decay shortening is stronger for Q-case. The last tendency correlates with the observed decrease of the extra-ligand fluorescence quantum efficiency for these two triads.

In toluene at $293 \mathrm{~K}$, our preliminary femtosecond pump-probe data for the triad $\mathrm{V}$, $(\mathrm{ZnOEP})_{2} \mathrm{Ph}-\mathrm{Pim} \otimes \mathrm{H}_{2} \mathrm{P}\left(m^{\wedge} \mathrm{Pyr}\right)_{2}$-(iso-PrPh $)_{2}$ reveal that the non-radiative deactivation of the dimer locally excited $S_{1}$-state may take place within $\tau_{1}=0.9 \mathrm{ps}$. In fact, TCSPC data discussed above, reflect the final steps of the electronic energy excitation dynamics in A-containing triads. Nevertheless, in toluene at $293 \mathrm{~K}$ the non-radiative relaxation processes for both the dimer and extraligand are faster in A-containing triads with respect to those found for A-free triads.

Schematic energy level diagram of excited states for A-containing triads is presented in Fig. 15. We now like to discuss possible pathways which might cause the observed shortening of the dimer and the extra-ligand locally excited $S_{1}$-states. In this respect, we will take into account our data and the results on ET studies in other covalently linked diporphyrin-quinone systems [29,68], self-assembled Q-containing porphyrin triads [49] and carotenoid-porphyrin-pyromellitimide triads [82], which have been interpreted in terms of long-distance ET mediated by superexchange interactions $[8,10,11,83]$.

Being directly populated (at $\lambda_{\mathrm{ex}}=545-555 \mathrm{~nm}$ ), the locally excited $\mathrm{S}_{1}$-state of the dimer $(\mathrm{ZnOEP})_{2}$ $\mathrm{Ph}$ in the triad may be deactivated as a result of the following non-radiative processes:

(i) one-step ET $\left(\right.$ Lig . . ${ }^{1}$ Dimer $\left.^{*} \cdots \mathrm{A}\right) \stackrel{k_{9}}{\rightarrow}(\mathrm{Lig} \cdot$. Dimer $^{+} \cdots \mathrm{A}^{-}$), with a rate constant $k_{9}=0.66 \times$ $10^{10} \mathrm{~s}^{-1}$ and $2.86 \times 10^{10} \mathrm{~s}^{-1}$ for Pim and Q, respectively (Table 2 );

(ii) one-step ET $\left(\operatorname{Lig} \cdots{ }^{1} \operatorname{Dimer}^{*} \cdots \mathrm{A}\right) \stackrel{k_{6}}{\rightarrow}\left(\mathrm{Lig}^{-}\right.$ ... Dimer ${ }^{+}$...A) with a rate constant $k_{6}$ or

(iii) S-S EET $\left(\operatorname{Lig} \ldots{ }^{1}\right.$ Dimer $^{*} \ldots$ A $) \stackrel{k_{5}}{\rightarrow}\left({ }^{1}\right.$ Lig $^{*} \ldots$ Dimer $\cdots A)$ with a rate constant $k_{5}$.

According to results of Section $3.2\left(k_{5}+k_{6}\right)=$ $1 / 1.7 \mathrm{ps}=5.9 \times 10^{11} \mathrm{~s}^{-1}$, and, correspondingly, $\left(k_{5}+k_{6}\right) \gg k_{9}$. It means that for A-containing triads in toluene at $293 \mathrm{~K}$, the direct one-step ET $\left(\operatorname{Lig} \cdots{ }^{1}\right.$ Dimer $\left.^{*} \ldots \mathrm{A}\right) \rightarrow\left(\operatorname{Lig} \ldots \operatorname{Dimer}^{+} \ldots \mathrm{A}^{-}\right)$ is low probable with respect to processes (ii) and (iii). Intrinsic (radiative + non-radiative) rate constant $k_{1}$ for the coordinated (pyridinated) dimer 

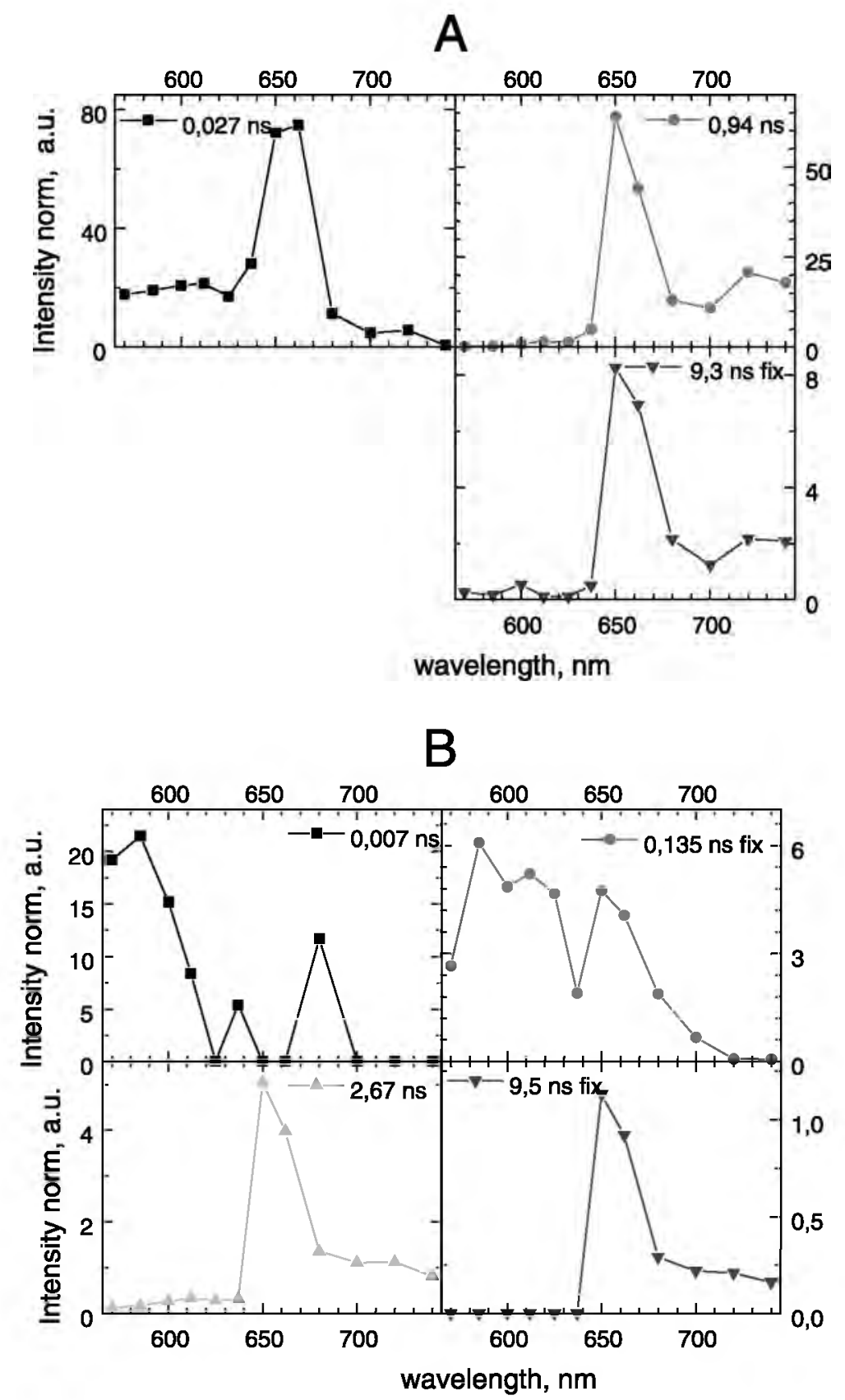

Fig. 14. Decay-associated spectra of the triad IV, $(\mathrm{ZnOEP})_{2} \mathrm{Ph}-\mathrm{Q} \otimes \mathrm{H}_{2} \mathrm{P}\left(m^{\wedge} \mathrm{Pyr}\right)_{2}-(\text { iso-PrPh})_{2}$ (A) and V, ( $\left.\mathrm{ZnOEP}\right)_{2} \mathrm{Ph}-$ $\mathbf{P i m} \otimes \mathrm{H}_{2} \mathrm{P}\left(m^{\wedge} \mathbf{P y r}\right)_{2}$-(iso-PrPh $)_{2}(\mathrm{~B})$ (toluene, $\left.293 \mathrm{~K}, \lambda_{\mathrm{ex}}=546 \mathrm{~nm}\right)$ derived from global analysis of 12 TCSPC time-resolved fluorescence measurements.

$(\mathrm{ZnOEP})_{2} \mathrm{Ph} \quad\left(k_{1}=1 / \tau_{\mathrm{S}}^{0}=1 / 1.15 \mathrm{~ns}=8.7 \times 10^{8}\right.$ $\mathrm{s}^{-1}$, Table 3$)$ is also essentially smaller than $\left(k_{5}+k_{6}\right)$ and $k_{9}$, respectively. Thus no detectable dimer fluorescence is observed for triads without and with $\mathrm{A}$. The co-operative action of all three processes in A-containing triads leads to the dimer 
Table 4

Measured and estimated parameters for superexchange ET in triads with electron acceptors (toluene, $293 \mathrm{~K}$ )

\begin{tabular}{|c|c|c|c|c|c|c|c|c|c|c|c|}
\hline Triad & Donor & Bridge & $\mathrm{A}$ & $\begin{array}{l}E\left(\mathrm{~S}_{1}^{\mathrm{D}}\right)^{\mathrm{a}} \\
(\mathrm{eV})\end{array}$ & $\begin{array}{l}r_{\mathrm{DB}}^{\mathrm{b}} \\
(\AA)\end{array}$ & $\begin{array}{l}r_{\mathrm{DA}}{ }^{\mathrm{b}} \\
(\AA)\end{array}$ & $\begin{array}{l}E_{\mathrm{D}}^{\mathrm{oxc}} \\
(\mathrm{eV})\end{array}$ & $\begin{array}{l}E_{\mathrm{D}^{+} \mathrm{B}^{-} \mathrm{A}^{\mathrm{d}}}(\mathrm{eV})\end{array}$ & $\begin{array}{l}\tau_{\mathrm{So}}^{\mathrm{De}} \\
(\mathrm{ns})\end{array}$ & $\begin{array}{l}\tau_{\mathrm{s}}^{\mathrm{Df}} \\
(\mathrm{ns})\end{array}$ & $\begin{array}{l}k_{\text {superexchange }} \times \\
10^{8} \mathrm{~s}^{-1 \mathrm{~g}}\end{array}$ \\
\hline IIIA & $\mathrm{H}_{2} \mathrm{P}(m \text {-Pyr })_{2}$-(iso-PrPh $)_{2}$ & $(\mathrm{ZnOEP})_{2} \mathrm{Ph}$ & $\mathrm{Q}$ & 1.91 & 8.2 & 18.0 & 1.10 & 3.08 & 6.2 & 0.94 & 9.0 \\
\hline IIIB & $\mathrm{H}_{2} \mathrm{Chl}(m-\mathrm{Pyr})_{2}$ & $(\mathrm{ZnOEP})_{2} \mathrm{Ph}$ & Q & 1.89 & 8.2 & 18.0 & 1.07 & 3.05 & 6.6 & 1.24 & 6.5 \\
\hline IIIC & $\mathrm{H}_{2} \mathrm{THP}(m-\mathrm{Pyr})_{2}$ & $(\mathrm{ZnOEP})_{2} \mathrm{Ph}$ & $\mathrm{Q}$ & 1.66 & 8.2 & 18.0 & 1.09 & 3.07 & 4.3 & 1.04 & 7.3 \\
\hline IV & $\mathrm{H}_{2} \mathbf{P}\left(m^{\wedge} \mathbf{P y r}\right)_{2}$-(iso- $\left.\mathrm{Pr} \mathbf{P h}\right)_{2}$ & $(\mathrm{ZnOEP})_{2} \mathrm{Ph}$ & $\mathrm{Q}$ & 1.91 & 9.1 & 20.8 & 1.10 & 3.08 & 7.7 & 0.95 & 9.2 \\
\hline $\mathrm{V}$ & $\mathbf{H}_{2} \mathbf{P}\left(m^{\wedge} \mathbf{P y r}\right)_{2}$-(iso- $\left.\mathbf{P r P h}\right)_{2}$ & $(\mathrm{ZnOEP})_{2} \mathrm{Ph}$ & Pim & 1.91 & 9.1 & 24.2 & 1.10 & 3.08 & 7.7 & 2.67 & 2.5 \\
\hline
\end{tabular}

The structures of the triads IIIA, IIIB, IIIC, IV and $\mathrm{V}$ are shown in Fig. 2.

${ }^{a}$ The energy levels of the extra-ligand (D) locally excited $S_{1}$-states were determined on the basis of the corresponding fluorescence and absorption $Q(0,0)$ bands.

${ }^{\mathrm{b}}$ Intercenter distances $r_{\mathrm{DB}}$ (donor-bridge) and $r_{\mathrm{DA}}$ (donor-acceptor) and were estimated from optimised structures of the triads (HyperChem software package, release

4, semiempirical method PM3). $r_{\mathrm{D}}=r_{\mathrm{B}} 5.5 \AA$, acceptor radii were taken to be $r_{\mathrm{A}}=3.5 \AA$ (Pim) and $r_{\mathrm{A}}=3.3 \AA(\mathrm{Q})$.

${ }^{\mathrm{c}}$ Oxidation potentials for extra-ligands have been extracted from literature data (in DMF vs SCE) $[78,79,81]$ taking into account the influence of pyridyl substituents on redox properties $[80,81]$. The reduction potential for coordinated dimer $(\mathrm{ZnOEP})_{2} \mathrm{Ph}$, bridge, was taken to be $E_{\mathrm{B}}^{\text {red }}=-1.69 \mathrm{~V}$ in DMSO $(\varepsilon=46.45)$ vs $\mathrm{SCE}$ measured with a supporting electrolyte tetrabutylammonium perchlorate [78] being coordinated to the porphyrin central $\mathrm{Zn}$ ion [60].

${ }^{\mathrm{d}}$ The energy $E_{\mathrm{D}^{+} \mathrm{B}^{-} \mathrm{A}}$ of mediating bridge level in toluene was estimated by $E_{\mathrm{D}^{+} \mathrm{B}^{-} \mathrm{A}}=e\left(E_{\mathrm{D}}^{\mathrm{ox}}-E_{\mathrm{A}}^{\text {red }}\right)+\Delta G_{\mathrm{S}}[63,64]$ (see the description for Table 2).

${ }^{\mathrm{e}} \tau_{\mathrm{S} 0}^{\mathrm{D}}$ values correspond to fluorescence decays measured for extra-ligands in triads without additional electron acceptor (see $\tau_{1}$ values in Table 3 ).

${ }^{\mathrm{f}} \tau_{\mathrm{S}}^{\mathrm{D}}$ values were attributed to the complexed extra-ligand according to decay-associated spectra from TCSPC data analysis.

${ }^{g}$ Rate constants for the superexchange ET were calculated by $k_{\text {superexchange }}=\left(\tau_{\mathrm{S}}^{\mathrm{D}}\right)^{-1}-\left(\tau_{\mathrm{S} 0}^{\mathrm{D}}\right)^{-1}$

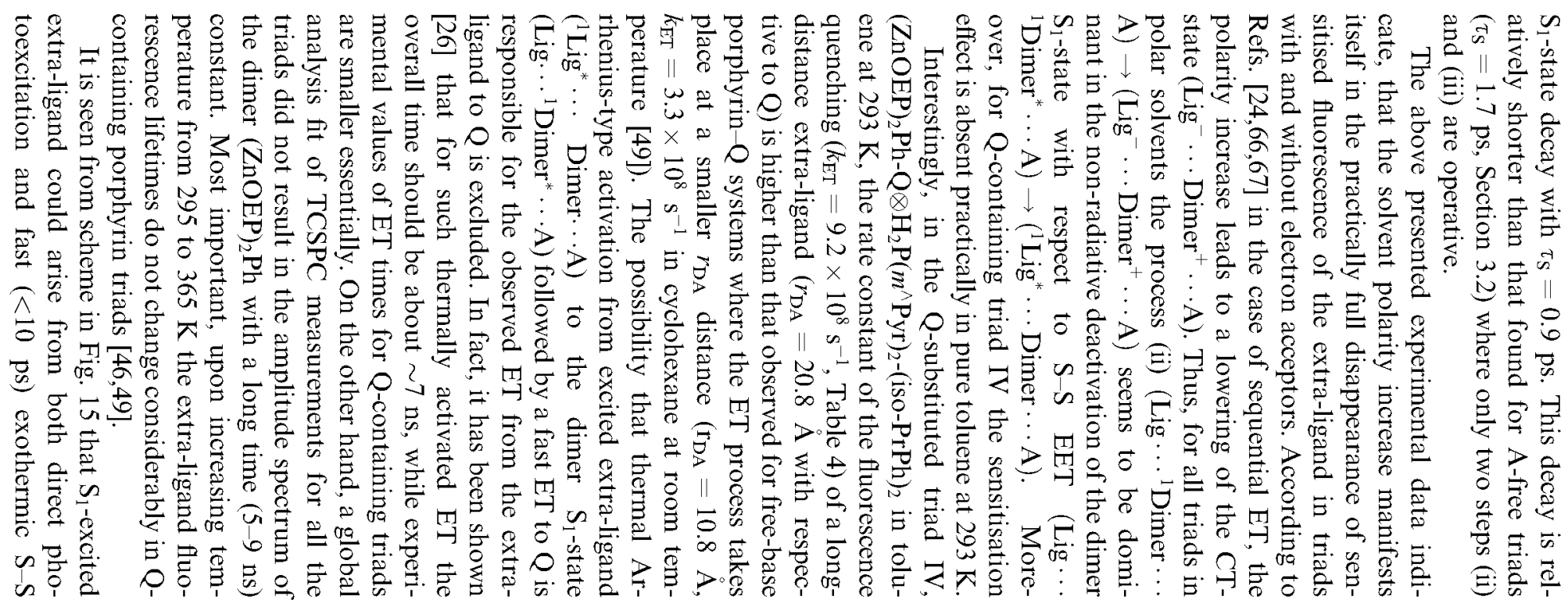




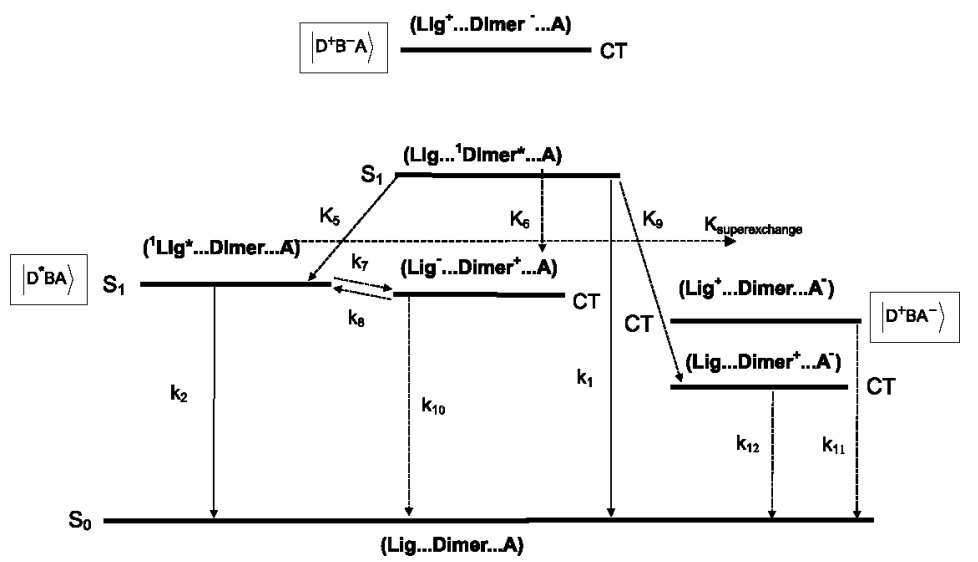

Fig. 15. Schematic energy level diagram of excited states for triads with electron acceptors. $\left|\mathrm{D}^{*} \mathrm{BA}\right\rangle$ state corresponds to the excited ex tra-ligand in the triad $\left({ }^{1} \mathrm{Lig}^{*} \cdots\right.$ Dimer $\left.\cdots A\right),\left|\mathrm{D}^{+} \mathrm{B}^{-} \mathrm{A}\right\rangle$ to $\left(\mathrm{Lig}^{+} \cdots \operatorname{Dimer}{ }^{-} \cdots \mathrm{A}\right)$ and $\left|\mathrm{D}^{+} \mathrm{BA}^{-}\right\rangle$to $\left(\mathrm{Lig}^{+} \cdots\right.$ Dimer $\left.\cdots \mathrm{A}^{-}\right)$. Here, $\mathrm{D}$ (donor) are extra-ligands (Lig) of various chemical nature (porphyrin, chlorin, tetrahydroporphyrin), $\mathrm{B}$ is a bridge, the dimer $(\mathrm{ZnOEP})_{2} \mathrm{Ph}$ (Dimer), and $\mathrm{A}$ are electron acceptors (quinone or pyromellitimide).

EET $\left(\operatorname{Lig} \cdots{ }^{1}\right.$ Dimer $\left.^{*} \cdots \mathrm{A}\right) \rightarrow\left({ }^{1} \operatorname{Lig}^{*} \cdots\right.$ Dimer $\cdots$ A). At $293 \mathrm{~K}$ in toluene, the additional repopulation of the extra-ligand $S_{1}$-state may be realised also upon the dimer excitation followed by the photoinduced ET and thermally activated charge recombination: (Lig ... ${ }^{1}$ Dimer $\left.^{*} \ldots \mathrm{A}\right) \stackrel{k_{6}}{\rightarrow}\left(\mathrm{Lig}^{-} \ldots\right.$ Dimer $\left.^{+} \ldots \mathrm{A}\right) \stackrel{k_{8}}{\rightarrow}\left(\right.$ Dimer $\left.\cdots{ }^{1} \mathrm{Lig}^{*} \ldots \mathrm{A}\right)$ (see Section 3.2). Following the above results and literature data, we may consider that, once formed, the locally excited $S_{1}$-state of the extra-ligand may decay via two non-radiative processes:

(iv) long-distance superexchange ET, discussed in Refs. $[8,10,11,29,49,68,82,83]\left({ }^{1}\right.$ Lig $^{*} \ldots$ Dimer $\cdots A) \stackrel{k_{\text {superexchange }}}{\longrightarrow}\left(\mathrm{Lig}^{+} \cdots\right.$ Dimer $\left.\cdots \mathrm{A}^{-}\right)$, and

(v) photoinduced hole transfer $\left({ }^{1} \mathrm{Lig}^{*} \ldots\right.$ Dimer …A $) \stackrel{k_{7}}{\rightarrow}\left(\mathrm{Lig}^{-} \ldots\right.$ Dimer $^{+} \ldots$ A $)$.

As has been outlined in detail $[8,10,83]$, superexchange ET occurs because of coherent mixing of three or more states of the system. Like it has been discussed for Q-containing porphyrin triads in Ref. [49], in our case these states are as follows (Fig. 15): $\left|\mathrm{D}^{*} \mathrm{BA}\right\rangle$ corresponds to $\left({ }^{1} \mathrm{Lig}^{*} \ldots\right.$ Dimer ... A), $\left|\mathrm{D}^{+} \mathrm{B}^{-} A\right\rangle$ to $\left(\mathrm{Lig}^{+} \ldots \mathrm{Dimer}^{-} \ldots \mathrm{A}\right)$ and $\left|\mathrm{D}^{+} \mathrm{BA}^{-}\right\rangle$to $\left(\mathrm{Lig}^{+} \ldots\right.$ Dimer $\left.\cdots \mathrm{A}^{-}\right)$. Here, the dimer $(\mathrm{ZnOEP})_{2} \mathrm{Ph}$ plays the role of the bridge which does not directly participate in ET process but lowers the barrier of ET reaction. Distant D and $A$ can exchange their charges through the bridge, that is a high-lying "spectator" state
$\left|\mathrm{D}^{+} \mathrm{B}^{-} \mathrm{A}\right\rangle$ mediates the ET from a donor state $\left|\mathrm{D}^{*} \mathrm{BA}\right\rangle$ to $\mathrm{CT}$-state $\left|\mathrm{D}^{+} \mathrm{BA}^{-}\right\rangle$. Within the superexchange model the charge separation rate $k_{\text {superexchange }}$ is proportional to $\left(V_{12} V_{23} / \delta E\right) . V_{12}$ and $V_{23}$ correspond to the electronic coupling terms for ET processes $\left|\mathrm{D}^{*} \mathrm{BA}\right\rangle \rightarrow\left|\mathrm{D}^{+} \mathrm{B}^{-} \mathrm{A}\right\rangle$ and $\left|\mathrm{D}^{+} \mathrm{B}^{-} \mathrm{A}\right\rangle$ $\rightarrow\left|\mathrm{D}^{+} \mathrm{BA}^{-}\right\rangle$, respectively, and $\delta E$ is the energy difference of $\left|\mathrm{D}^{+} \mathrm{B}^{-} \mathrm{A}\right\rangle$ and the crossing point of the potential energy curves of $\left|\mathrm{D}^{*} \mathrm{BA}\right\rangle$ and $\left|\mathrm{D}^{+} \mathrm{BA}^{-}\right\rangle$along the reaction co-ordinate. The values of the couplings $V_{12}$ and $V_{23}$ are essentially lower than the energy differences between the relevant system states.

In toluene at $293 \mathrm{~K}$ for Q-containing triads IIIA and IV of different geometry with the same extraligand, superexchange ET rate constants are maximal and practically independent on the triad geometry (Table 4). This fact may be explained by a close proximity of extra-ligand macrocycles to $\pi$ conjugated electronic system of the dimer. In a result, the electronic coupling term $V_{12}$ is strong enough and does not change essentially upon the geometrical reorganisation of the same electron acceptor in the triad, while the $V_{23}$ term remains constant. One-step ET process (ii) in the triad $(\mathrm{ZnOEP})_{2} \mathrm{Ph} \otimes \mathrm{H}_{2} \mathrm{P}\left(m^{\wedge} \mathrm{Pyr}\right)_{2}$-(iso- $\left.\mathrm{PrPh}\right)_{2}$ may take place with the rate constant of $k_{\mathrm{ET}}=5.9 \times 10^{11} \mathrm{~s}^{-1}$ (Section 3.2). Correspondingly, it follows from the Eq. (1) and estimated energies of $\lambda \approx 0.33 \mathrm{eV}$ and 
$\Delta G^{0}=-0.23 \mathrm{eV}$ that the electronic coupling term for ET process $\left|\mathrm{D}^{*} \mathrm{BA}\right\rangle \rightarrow\left|\mathrm{D}^{+} \mathrm{B}^{-} \mathrm{A}\right\rangle$ is of $V_{12} \approx 9.1$ meV.

Data of Table 4 show that in Q-containing triads of the same geometry and various extra-ligands (IIIA, IIIB, IIIC) ET rate constants for $\mathrm{H}_{2} \mathrm{Ch} l(m-\mathrm{Pyr})_{2}$ (IIIB) and $\mathrm{H}_{2} \mathrm{THP}(m-\mathrm{Pyr})_{2}$ (IIIC) are smaller with respect to that found for $\mathrm{H}_{2} \mathrm{P}(\mathrm{m}$ $\mathrm{Pyr}_{2}$-(iso- $\left.\mathrm{PrPh}\right)_{2}$ (IIIA). These differences may be attributed to relative changes of some factors depending on the nature of the extra-ligand: the energy of $\left|D^{*} B A\right\rangle,\left|D^{+} B^{-} A\right\rangle$ and $\left|D^{+} B A^{-}\right\rangle$states, and the electronic coupling term $V_{12}$ At last, for triads having the same geometry and extra-ligand but different acceptors, the observed decrease of ET rate constant for Pim-containing triad V $\left(k_{\mathrm{ET}}=2.5 \times 10^{8} \mathrm{~s}^{-1}\right)$ with respect to that for Qcontaining triad IV $\left(k_{\mathrm{ET}}=9.2 \times 10^{8} \mathrm{~s}^{-1}\right)$ may be due to the increase of $r_{\mathrm{DB}}$ and $r_{\mathrm{DA}}$ distances as well as changes of the energy of $\left|\mathrm{D}^{+} \mathrm{B}^{-} \mathrm{A}\right\rangle$ and $\left|\mathrm{D}^{+} \mathrm{BA}^{-}\right\rangle$states.

The decrease of the extra-ligand fluorescence quantum efficiency upon the solvent polarity rise found for triads IV and $V$, reflects the ET rate increase in these systems. These results may be explained within theoretical approximations applied to porphyrin-Q arrays with superexchange ET [83]. An increase of the solvent dielectric constant lowers the energies of the bridge $\left|\mathrm{D}^{+} \mathrm{B}^{-} \mathrm{A}\right\rangle$ and acceptor $\left|\mathrm{D}^{+} \mathrm{BA}^{-}\right\rangle$states and increases the system-bath interaction and, consequently, the relaxation coefficients. The independence of superexchange ET rates on temperature observed for Q-containing porphyrin triads [46] could be explained by a small temperature dependence of the Franck-Condon factor for ET [68].

Finally we would like to discuss the other pathway of the non-radiative deactivation of the extra-ligand $\mathrm{S}_{1}$-state, a hole transfer process $(\mathrm{v})$. As it was discussed above (Section 3.2), the photoinduced hole transfer in A-free triads $\left({ }^{1} \mathrm{Lig}^{*} \ldots\right.$ Dimer $) \stackrel{k_{7}}{\rightarrow}\left(\mathrm{Lig}^{-} \ldots\right.$ Dimer $\left.^{+}\right) \quad$ becomes more effective upon the lowering of the final CTstate $\left(\mathrm{Lig}^{-} \ldots\right.$ Dimer $\left.^{+}\right)$caused by the solvent polarity increase. In fact, for A-containing triads the same CT-state $\left(\mathrm{Lig}^{-} \ldots\right.$ Dimer $\left.^{+} \ldots \mathrm{A}\right)$ is populated also via a hole transfer from the extra-ligand or ET from the dimer, with both processes being accelerated by the polarity increase. As is seen in scheme of Fig. 15 this $\left(\mathrm{Lig}^{-}\right.$... Dimer ${ }^{+}$... A) state is not the energetically lowest CT-state in A-containing triads. Indeed, the subsequent charge separation between $\left(\mathrm{Lig}^{-} \ldots\right.$ Dimer $\left.^{+} \ldots \mathrm{A}\right)$ and two lower-lying CT-states, $\left(\operatorname{Lig} \cdots \operatorname{Dimer}^{+} \ldots \mathrm{A}^{-}\right)$and $\left(\mathrm{Lig}^{+} \cdot \mathrm{Dimer} \cdot \mathrm{A} \mathrm{A}^{-}\right)$, may be taken into account. Both ET pathways, $\left(\mathrm{Lig}^{-} \ldots \mathrm{Dimer}^{+} \ldots \mathrm{A}\right)$ $\rightarrow\left(\operatorname{Lig} \ldots \operatorname{Dimer}^{+} \ldots \mathrm{A}^{-}\right)$and $\left(\mathrm{Lig}^{-} \ldots\right.$ Dimer $^{+}$ $\cdots A) \rightarrow\left(\operatorname{Lig}^{+} \ldots\right.$ Dimer $\left.\cdots A^{-}\right)$, should include $\mathrm{CT}$ from a long-distance porphyrin extra-ligand to A ( $Q$ or Pim). In this respect, these two steps may also be considered as superexchange ET processes mediated by coherent mixing of the corresponding upper lying CT-states in A-containing triads. The first process $\left(\mathrm{Lig}^{-} \ldots \mathrm{Dimer}^{+} \ldots \mathrm{A}\right) \rightarrow(\mathrm{Lig} .$. Dimer $\left.^{+} \cdot \mathrm{A}^{-}\right)$is a one-ET reaction, while the second $\left(\mathrm{Lig}^{-} \ldots\right.$ Dimer $\left.^{+} \ldots \mathrm{A}\right) \rightarrow\left(\mathrm{Lig}^{+} \ldots\right.$ Dimer $\cdots \mathrm{A}^{-}$) may be attributed to a two-ET reaction as discussed recently in Refs. $[84,85]$.

In order to get a better understanding of the complex ET dynamics in the triads with electron acceptors further experiments, using variation of temperature, polarity and comprehensive pumpprobe measurements, are under way.

\section{Conclusions}

Self-assembled porphyrin triads III, IV and V, containing the main biomimetic components, $\mathrm{Zn}$ porphyrin dimer, free-base tetrapyrrole macrocycle (porphyrin, chlorin or tetrahydroporphyrin), and electron acceptor (quinone or pyromellitimide) are appropriate synthetic systems suitable for modelling the primary charge separation in vivo. In addition, these studies may also provide a foundation for the design of synthetic integrated multimolecular nanodevices and related advanced materials for use in photovoltaic energy conversion/charge storage, optical sensing, photosensitisation, gating and other applications.

The presently discussed steady-state and timeresolved experiments show complex energy and ET dynamics, depending on the triad geometry, redox and photophysical properties of interacting subunits as well as on a temperature and polarity 
of the solvent. A strong quenching of the dimer $S_{1}$ state in the triads originates from both energy and sequential ET processes from the dimer to the extra-ligand which are faster with respect to a slower ET from the dimer to covalently linked acceptors ( $\mathrm{Q}$ or $\mathrm{Pim})$. A non-radiative deactivation of the extra-ligand $S_{1}$-state is due to competing processes, long-range superexchange ET to an acceptor, and photoinduced hole transfer from the extra-ligand to the dimer followed by possible superexchange ET steps to low-lying CT states of the triads. It is expected that continued work with these systems will better define time scale and interplay between numerous non-radiative pathways in order to optimise the structure and energy conversion dynamics.

\section{Acknowledgements}

This work was supported by Volkswagenschtiftung (grant 1/72 171), DFG Schwerpunktprogramm (SPP 470, Schr 231) and the National Foundation for Basic Research of Belarus (grant no. $\mathrm{Ph}$ 99-104).

\section{References}

[1] J. Fan, J.A. Whiteford, B. Olenyuk, M.D. Levin, P.J. Stang, E.B. Fleischer, J. Am. Chem. Soc. 121 (1999) 2741.

[2] K.E. McAuley, P.K. Fyfe, R.J. Cogdell, N.W. Isaacs, M.R. Jones, FEBS Lett. (2000) 285.

[3] K.-H. Rhee, E.P. Morris, J. Barber, W. Kuhlbrandt, Nature 396 (1998) 283.

[4] X. Hu, A. Damjanovic, T. Ritz, K. Shulten, Proc. Natl. Acad. Sci. USA 95 (1998) 5935.

[5] H. van Amerongen, R. van Grondele, J. Phys. Chem. B 105 (2001) 604.

[6] J. Deisenhofer, O. Epp, K. Miki, R. Huber, H. Michel, J. Biol. Chem. 180 (1984) 385.

[7] L. Laporte, C. Kirmaier, C. Schenck, D. Holten, Chem. Phys. 197 (1995) 225.

[8] M. Bixon, J. Jortner, M.E. Michel-Beyerle, Chem. Phys. 197 (1995) 389, and references therein.

[9] S. Schmidt, T. Arlet, P. Hamm, H. Huber, T. Nagele, J. Wachteveitl, M. Meyer, H. Scheer, W. Zinth, Chem. Phys. Lett. 223 (1994) 116.

[10] W. Davis, M.R. Wasielewski, M. Ratner, V. Mujica, A. Nitzan, J. Phys. Chem. 101 (1997) 6158.
[11] M. Schreiber, D. Kilin, U. Kleinekathofer, J. Lumin. 83-84 (1999) 235.

[12] V. Balzani, F. Scandola, Supramolecular Photochemistry, Ellis Horwoord, New York, London, Toronto, Sydney, Tokyo, Singapore, 1991.

[13] M.C. Petty, M.R. Bryce, D. Bloor (Eds.), An Introduction to Molecular Electronics, Edward Arnold, a division of Holder Headline PLC, London, Melbourn, Auckland, 1995.

[14] R.T. Hayes, M.R. Wasielewski, D. Gosztola, J. Am. Chem. Soc. 122 (2000) 5563.

[15] J.P. Sumida, P.A. Liddell, S. Lin, A.N. Macpherson, G.R. Seely, A. Moore, T.A. Moore, D. Gust, J. Phys. Chem. A 102 (1998) 5512.

[16] R.W. Wagner, J. Seth, S.I. Yang, D. Kim, D.F. Bocian, D. Holten, J.S. Lindsey, J. Org. Chem. 63 (1998) 5042.

[17] T. Yamazaki, I. Yamazaki, A. Osuka, J. Phys. Chem. B 102 (1998) 7858.

[18] E.I. Zenkevich, A.M. Shulga, S.M. Bachilo, U. Rempel, J. von Richthofen, C. von Borczyskowski, J. Lumin. 76\&77 (1998) 354.

[19] J.J. Piet, P.N. Taylor, B.R. Wegewijs, H.L. Anderson, A. Osuka, J.M. Warman, J. Phys. Chem. B 105 (2001) 97.

[20] M.R. Wasielewski, D.J. Johnson, W.A. Swec, K.M. Kersey, D.W. Minsek, J. Am. Chem. Soc. 110 (1988) 7219 .

[21] D.J. Johnson, M.P. Niemczyk, D.W. Minsek, G.P. Wiererrechy, W.A. Svec, G.L. Gaines III, M.R. Wasielewski, J. Am. Chem. Soc. 115 (1993) 5692.

[22] J.L. Sessler, M.R. Johnson, T.-Y. Lin, Tetrahedron 165 (1989) 392.

[23] A. Osuka, K. Maruyama, I. Yamazaki, J. Chem. Phys. Lett. 45 (1990) 4767.

[24] M.R. Wasielewski, G.L. Gaines III, M.P. O'Neil, W.A. Svec, M.P. Niemczyk, L. Prodi, D. Gosztola, in: N. Mataga, T. Okada, H. Masuhara (Eds.), Dynamics and Mechanisms of Photoinduced Transfer and Related Phenomena, Elsevier Science Publishers, New York, 1992, pp. 87-103.

[25] D. Gust, T.A. Moore, A.L. Moore, C. Devados, P.A. Liddell, R. Hermant, R.A. Nieman, L.G. Demanche, J.M. DeGraziano, I. Gouni, J. Am. Chem. Soc. 114 (1992) 3590.

[26] U. Rempel, B. von Maltzan, C. von Borczyskowski, J. Lumin. 53 (1992) 175.

[27] D. Gust, T.A. Moore, A.L. Moore, A.N. Macpherson, A. Lopez, J.M. DeGraziano, I. Gouni, E. Bittesmann, G.R. Seely, F. Gao, R.A. Nieman, X.C. Ma, L. Demanche, D.K. Luttrull, S.-J. Lee, P.K. Kerrigan, J. Am. Chem. Soc. 115 (1993) 11141.

[28] V.V. Borovkov, R.P. Evstigneeva, A.A. Gribkov, Khimiya. Geterotziklich. Soedinenii 3 (1995) 343.

[29] U. Rempel, B. von Maltzan, C. von Borezyskowski, Chem. Phys. Lett. 245 (1995) 253.

[30] A. Harriman, J.-P. Sauvage, Chem. Soc. Rev. 25 (1996) 41- 48 .

[31] A. Starukhin, E. Zenkevich, A. Shulga, A. Chernook, J. Lumin. 68 (1996) 313. 
[32] A. Osuka, S. Marumo, N. Mataga, S. Taniguchi, T. Okada, I. Yamazaki, Y. Nishimura, T. Ohno, K. Nozaki, J. Am. Chem. Soc. 118 (1996) 155.

[33] E.I. Zenkevich, V.N. Knyukshto, A.M. Shulga, V.A. Kuzmitzkii, V.I. Gael, E.G. Levinson, A.F. Mironov, J. Lumin. 75 (1997) 229.

[34] D. Kuciauskas, P.A. Liddell, S.-C. Hung, S. Lin, S. Stone, G.R. Seely, A.L. Moore, T.A. Moore, D. Gust, J. Phys. Chem. B 101 (1997) 429.

[35] J. Andreasson, J. Kajanus, J. Martensson, B. Albinsson, J. Am. Chem. Soc. 122 (2000) 98.

[36] S.I. Yang, R.K. Lammi, J. Seth, J.A. Riggs, T. Arai, D. Kim, D.F. Bocian, D. Holten, J.S. Lindsey, J. Phys. Chem. B 102 (1998) 9426.

[37] J. Liu, J.R. Bolton, J. Phys. Chem. 96 (1992) 1718.

[38] K.D. Truong, A.D. Bondrauk, T.H. Tran-Thi, P. Grenier, D. Houde, S. Palacin, Thin Solid Films 244 (1994) 981.

[39] A. Berg, M. Rachamim, T. Galili, H. Levan on, J. Phys. Chem. 10 (1996) 8791.

[40] J.L. Sessler, B. Wang, A. Harriman, J. Am. Chem. Soc. 117 (1995) 704.

[41] H. Tamiaki, M. Amakawa, Y. Shimono, R. Tanikaga, A.R. Holzwarth, K. Schaffner, Photochem. Photobiol. 63 (1996) 92.

[42] H.L. Anderson, C.A. Hunter, J.K.M. Sanders, J. Chem. Soc., Chem. Commun. (1996) 1361.

[43] J.A.I. Oksanen, E.I. Zenkevich, V.N. Knyukshto, S. Pakalnis, P.H. Hynninen, J.E.I. Korrpi-Tommola, Biochimica Biophysica Acta-Bioenergetics 1321 (1997) 165.

[44] S. Bachilo, A. Willert, U. Rempel, A.M. Shulga, E.I. Zenkevich, C. von Borczyskowski, J. Photochem. Photobiol. A: Chemistry 126 (1999) 99.

[45] J.-M. Lehn, Frontiers, in: H.-J. Schneider, H. Durr (Eds.), Supramolecular Organic Chemistry and Photochemistry, Verlagsgesellschaft mbH VCH, Weiheim, New York, Basel, Cambridge, 1991, pp. 1-28.

[46] U. Rempel, B. von Maltzan, C. von Borczyskowski, Pure Appl. Chem. 65 (1993) 1681.

[47] A.V. Chernook, A.M. Shulga, E.I. Zenkevich, U. Rempel, C. von Borczyskowski, J. Phys. Chem. 100 (1996) 1918.

[48] A.V. Chernook, U. Rempel, C. von Borczyskowski, E.I. Zenkevich, A.M. Shulga, Chem. Phys. Lett. 254 (1996) 229.

[49] U. Rempel, S. Meyer, B. von Maltzan, C. von Borczyskowski, J. Lumin. 78 (1998) 97.

[50] H. Tamiaki, M. Amakawa, Y. Shimono, R. Tanikaga, A.R. Holzwarth, K. Schaffner, Photochem. Photobiol. 63 (1996) 92.

[51] T. Miyatake, H. Tamiaki, A.R. Holzwarth, K. Schaffner, Photochem. Photobiol. 69 (1999) 448.

[52] T. Nagata, A. Osuka, K. Maruyama, J. Am. Chem. Soc. 112 (1990) 3054.

[53] J.L. Sessler, V.L. Capuano, A. Harriman, J. Am. Chem. Soc. 115 (1993) 4618.

[54] F.R. Longo, J.D. Finarelli, J.B. Kim, J. Heterocycl. Chem. 6 (1969) 927.

[55] R.G. Little, J.A. Anton, P.A. Loach, J.A. Ibers, J. Heterocycl. Chem. 12 (1975) 343.
[56] H.W. Whitlock Jr., R. Hanauer, M.Y. Oester, B.K. Bower, J. Am. Chem. Soc. 91 (1969) 7485.

[57] D.V. O'Connor, D. Phillips, Time Correlated Single Photon Counting, Academic Press, London, 1984.

[58] S.L. Murrov, I. Carmichael, G.L. Hug, Handbook of Photochemistry, Marcel Dekker, New York, Basel, Hong Kong, 1993, p. 269-278.

[59] J.-H. Furhop, K.M. Kadish, D.G. Davis, J. Am. Chem. Soc. 95 (1973) 5140.

[60] D. Gust, T.A. Moore, A.L. Moore, H.K. Kang, J.M. DeGraziano, P.A. Liddell, G.R. Seely, J. Phys. Chem. 97 (1993) 13637

[61] T. Asahi, M. Ohkohchi, R. Matsusaka, N. Mataga, R.P. Zang, A. Osuka, K. Maruyama, J. Am. Chem. Soc. 115 (1993) 5665.

[62] R.A. Cormier, M.P. Posey, W.L. Bell, H.N. Fonda, J.S Connoly, Tetrahedron 45 (1989) 4831.

[63] D. Rehm, A. Weller, Isr. J. Chem. 8 (1970) 259.

[64] G.J. Kavarnos, N.J. Turro, Chem. Rev. 86 (1986) 401.

[65] J.-H. Furhop, D. Mauzerall, J. Am. Chem. Soc. 91 (1969) 4174.

[66] R.A. Marcus, Rev. Mod. Phys. 65 (1993) 599.

[67] H. Heitele, M.E. Michel-Beyerle, J. Am. Chem. Soc. 107 (1985) 8286.

[68] J. Rodriguez, C. Kirmaier, M.R. Johnson, R.A. Friesner, D. Holten, J.L. Sessler, J. Am. Chem. Soc. 113 (1991) 1652.

[69] E.I. Zenkevich, A.M. Shulga, A.V. Chernook, E.I. Sagun, G.P. Gurinovich, Proc. Ind. Acad. Sci., Chem. Sci. 107 (1995) 795-802.

[70] U. Rempel, B. von Maltzan, C. von Borczyskowski, Chem. Phys. Lett. 245 (1995) 253.

[71] M.R. Wasielewski, M.P. Niemczyk, in: M. Gouterman, P.M. Rentzepis, K.D. Straub (Eds.), Porphyrins - States and Dynamics, ACS Symposium Series No 321, American Chemical Society, Washington, DC, 1986, pp. 154-165.

[72] K. Kamioka, R.A. Cormier, T.W. Lutton, J.S. Connoly, J. Am. Chem. Soc. 114 (1992) 4414.

[73] J.-S. Hsiao, B.P. Krueger, R.W. Wagner, T.E. Johnson, J.K. Delaney, D.C. Mauzerall, G.R. Fleming, J.S. Lindsey, D.F. Bocian, R.J. Donohoe, J. Am. Chem. Soc. 118 (1996) 11181.

[74] Th. Foerster, Modern Quantum Chemistry, vol. 3, Academic Press, New York, 1965, pp. 93-118.

[75] S.I. Yang, R.K. Lammi, J. Seth, J.A. Riggs, T. Arai, D. Kim, D.F. Bocian, D. Holten, J.S. Lindsey, J. Phys. Chem. B 102 (1998) 9426.

[76] M.R. Wasielewski, D.G. Johnson, M.P. Niemczyk, G.L. Gains III, M.P. O’Neil, W.A. Svec, J. Am. Chem. Soc. 112 (1990) 6482.

[77] E.I. Zenkevich, S.M. Bachilo, A. Willert, U. Rempel, A.M. Shulga, C. von Borczyskowski, Int. J. Mater. Sci. Engng. C: Biomimetic Supramolec. Syst. in press.

[78] J.-H. Fuhrhop, K.M. Kadish, D.G. Davis, J. Am. Chem. Soc. 95 (1973) 5140.

[79] R. Felton, in: D. Dolphin (Ed.), The Porphyrins, vol. 5, Academic Press, New York, 1978, p. 53.

[80] P. Worthington, P. Hambright, R. Williams, J. Inorg. Biochem. 12 (1980) 281. 
[81] V.G. Majranowski, in: N.S. Enikolopyan (Ed.), Porphyrins: Spectroscopy, Photochemistry, Applications, Nauka, Moscow, 1987, pp. 127-181.

[82] A. Osuka, H. Yamada, K. Maruyama, N. Mataga, T. Asahi, M. Ohkoshi, T. Okada, I. Yamazaki, Y. Nishimura, J. Am. Chem. Soc. 115 (1973) 9439.
[83] D. Kilin, U. Kleinekathofer, M. Schreiber, J. Phys. Chem. A 104 (2000) 5413.

[84] T. Bandyopadhyay, A. Okada, M. Tachiya, J. Chem. Phys. 110 (1999) 9630.

[85] S.E. Miller, A.S. Lukas, E. Marsh, P. Bushard, M.R. Wasielewski, J. Am. Chem. Soc. 122 (2000) 7802. 